\title{
Co-hydrotreatment of Tire Pyrolysis Oil and Vegetable Oil for the Production of Transportation Fuels
}

\author{
Yinglei Han ${ }^{1}$, Filip Stankovikj ${ }^{1}$, Manuel Garcia Perez ${ }^{1 *}$ \\ ${ }^{1}$ Department of Biological Systems Engineering, Washington State University, Pullman, WA, \\ USA
}

(Paper to be submitted to Fuel Processing Technology)

\begin{abstract}
Catalytic hydrotreatment followed by products isomerization is an effective technology to convert vegetable oil to a green fuel composed of straight and branched chain aliphatic hydrocarbons. The content of aromatics in this fuel is very low. In this paper we study the co-hydrotreatment of vegetable oil and tires oil in the presence of a CoMo/ $\mathrm{Al}_{2} \mathrm{O}_{3}$ catalyst as a way of utilizing existing infrastructure created for vegetable oil processing for tire oil up-grading in order to obtain fuel cuts with aromatics. Hydrotreatment studies with different vegetable oil/tires oil blend ratios were conducted. The yield and composition of the resulting hydrotreated oils are reported. Aliphatic hydrocarbons ranging from $\mathrm{C} 7$ to $\mathrm{C} 20$ derived from vegetable oils and aromatics from $\mathrm{C} 6$ to $\mathrm{C} 16$ derived from the tire oil were identified as products. The resulting oils were then successfully distilled into naphtha, kerosene, diesel and gas oil cuts. The yield, chemical composition and the fuel properties of the transportation fuel cuts obtained are reported and compared with commercial petro derived fuels.
\end{abstract}

Keywords: Co-hydrotreatment, tire pyrolysis oil, vegetable oil, catalyst characterization, catalytic behavior, distillation, fuel characterization 
*Corresponding author:

Manuel Garcia-Perez

Associate Professor,

Biological Systems Engineering, WSU

LJ Smith, Room 205, Pullman, WA, 99164-6120

Phone: 509-335-7758,

Fax: 509-335-2722,

e-mail: mgarcia-perez@wsu.edu 


\section{Introduction}

The growing environmental concerns associated with the use of petroleum derived fossil fuels has stimulated recent interest in alternative fuels [1]. Fuels derived from vegetable oils and tires oil show promising potential in replacing a fraction of the current petroleum based transportation fuels. Vegetable oils can be readily converted into biodiesel via transesterification with alcohols (methanol or ethanol). However, biodiesel suffers from drawbacks such as limited storage stability and poor cold flow properties [2]. The hydrocarbons resulting from the hydrotreatment (decarboxylation, decarbonylation and hydrodeoxygenation) and isomerization of vegetable oils (rapeseed, palm, soybean, sunflower, castor, jatropha and cooking oil) have better fuel properties [3-9]. The production of green diesel through hydrodeoxygenation (HDO) technology by various catalysts, $\left(\mathrm{Pt} / \mathrm{C}, \mathrm{Pd} / \mathrm{C}, \mathrm{NiMo} / \mathrm{Al}_{2} \mathrm{O}_{3}\right.$ and $\left.\mathrm{CoMo} / \mathrm{Al}_{2} \mathrm{O}_{3}\right)$ has received considerable attention in the last 10 years [10-14]. The expensive noble metals (Pt and Pd) typically show the highest HDO activity for vegetable oils $[15,16]$. Cheaper bifunctional catalysts, such as the $\mathrm{NiMo} / \mathrm{Al}_{2} \mathrm{O}_{3}$ has also been used for vegetable oil hydrotreatment [17]. Typically NiMo is responsible for the $\mathrm{HDO}$ while the acidic $\mathrm{Al}_{2} \mathrm{O}_{3}$ support favors hydrocracking [18, 19]. Kubicka et al [4] illustrated the importance of $\mathrm{Mo}$ in the $\mathrm{NiMo} / \mathrm{Al}_{2} \mathrm{O}_{3}$ system, and proved that the activity of catalysts decreased in the order $\mathrm{NiMo} / \mathrm{Al}_{2} \mathrm{O}_{3}>\mathrm{Mo} / \mathrm{Al}_{2} \mathrm{O}_{3}>\mathrm{Ni} / \mathrm{Al}_{2} \mathrm{O}_{3}$ [5]. Wang et al used three different types of acidic support to investigate the effect of supports on catalyst activity and selectivity during hydrotreatment of soybean oil [20]. The results demonstrated that $\mathrm{NiMo} / \mathrm{Al}_{2} \mathrm{O}_{3}$ selectively favored the production of diesel ranged hydrocarbons. Naptha cuts were favored with zeolite-supported NiMo. The mesoporous $\mathrm{SiO}_{2}-\mathrm{Al}_{2} \mathrm{O}_{3}$ catalysts are more acidic than $\mathrm{Al}_{2} \mathrm{O}_{3}$ but less acidic than most of zeolites. $\mathrm{SiO}_{2}-\mathrm{Al}_{2} \mathrm{O}_{3}$ supported $\mathrm{Ni}$ is more selective for the kerosene 
range hydrocarbons than the less acidic $\mathrm{Al}_{2} \mathrm{O}_{3}$ which favors diesel range hydrocarbons [21]. Similar results have been reported for $\mathrm{Pt}$ and $\mathrm{Pb}$ supported catalysts [22-24]. $\mathrm{CoMo} / \mathrm{Al}_{2} \mathrm{O}_{3}$ is another commercial catalyst for hydrocarbons production by HDO of various triglycerides. This catalyst is considered as a moderate acidic catalyst which favors hydrocracking of straight chain hydrocarbons $[25,26]$.

The use of tire pyrolysis oil for the production of transportation fuels is much less studied than the vegetable oils. Pyrolysis converts between 40 to $60 \mathrm{wt} \%$ of tires into oil [27]. Tires pyrolytic oil has a very high calorific value $(44 \mathrm{MJ} / \mathrm{kg})$, very low ash content $(<0.05 \mathrm{wt}$. \%) and a relatively low sulfur content (0.8-1.5 wt. \%). Current jet fuel derived from fossil petroleum contains approximately 20 wt. \% of paraffin, 40 wt. \% iso-paraffin, 20 wt. \% naphthene and 20 wt. $\%$ aromatic compounds. The co-hydrotreatment of vegetable oil and tires oils offer an interesting opportunity to take advantage of existing infrastructure to process tires oil and to produce fuels with a content of aromatic comparable with its fossil fuel competitors.

In this study, the co-hydrotreatment on vegetable oil and pyrolysis oils derived from waste tires, were conducted using commercial $\mathrm{Co}-\mathrm{Mo} / \mathrm{Al}_{2} \mathrm{O}_{3}$ catalysts. The aim of co-hydrotreatment is to produce alternative fuels containing both aliphatic and aromatic hydrocarbons. The information collected will also be useful to understand the challenges and opportunities of co-processing tires oil in facilities built for the hydro-processing vegetable oils.

\section{Materials and methods}




\subsection{Materials and reagents}

The tire pyrolysis oil was provided by CONRAD Industries, Inc, Chehalis, WA. It was produced from shredded waste tires in a rotating kiln. The pyrolysis vapors were condensed using a spray condenser tower. The Canola oil studied was a commercial oil (Walmart Great Value: Canola Oil. 53507-GRV). The chemical make-up of the vegetable oil studied was analyzed by transesterification with methanol and analysis of the resulting samples by GC/FID (FAMEWAX column, 30 m x $320 \mu \mathrm{m}$ X $0.25 \mu \mathrm{m}$, Restek Corporation, Bellefonte, PA). The injector was kept at $260{ }^{\circ} \mathrm{C}$, with an injection volume of $1 \mu \mathrm{l}$ by split injection mode (ratio at 30:1). The initial oven temperature was set at $120{ }^{\circ} \mathrm{C}$, then increased at a heating rate of $3{ }^{\circ} \mathrm{C} / \mathrm{min}$ to $240{ }^{\circ} \mathrm{C}$ and held for $20 \mathrm{~min}$. The detector temperature was set at $250{ }^{\circ} \mathrm{C}$. Helium was used as carrier gas.

The $\mathrm{CoMo} / \gamma-\mathrm{Al}_{2} \mathrm{O}_{3}$ catalyst was purchased from Alfa Aesar (http://www.alfa.com/). Its nominal CoO-content was 2.9 wt. \%, its $\mathrm{MoO}_{3}$-content was 13.5 wt. \% and the BET surface area 193

$\mathrm{m}^{2} / \mathrm{g}$ [28]. The $\mathrm{CoMo} / \mathrm{Al}_{2} \mathrm{O}_{3}$ catalyst was delivered as pellets, with particle lenght higher than 50 $\mathrm{mm}$. The activity of such catalyst was low in our system, and therefore the pellets were ground into fine powder (between 0.1 and $0.5 \mathrm{~mm}$ ). All the solvents (acetone, methanol) used for cleaning the reactor and collecting the products were reagent grade. Those used for analysis were HPLC grade.

\subsection{Co-hydrotreatment tests}


Figure 1 shows a scheme with the tasks conducted. Different tire/canola oil mass ratio (4:1, 1:1, and 1:4) were preparing before hydrotreating. $100 \mathrm{~g}$ of the prepared blends were fed into reactor with $5 \mathrm{~g}$ of $\mathrm{CoMo} / \mathrm{Al}_{2} \mathrm{O}_{3}$ catalyst in each test. Each blend was hydrotreated in duplicate and the average results reported. The tests were conducted in a $250 \mathrm{~mL}$ Parr reactor (Model\# 4576A) with the stirring speed at $250 \mathrm{rpm}$. The initial pressure of hydrogen was $9.1 \mathrm{MPa}$ at room temperature $\left(25^{\circ} \mathrm{C}\right)$ and it took $30-35$ min to heat up to $350^{\circ} \mathrm{C}$. The final temperature was kept for another 4 hours before the reactor was cooled down to room temperature (see scheme of installation and typical operational conditions in Figure 2). Gaseous products were collected in gas sampling cylinders and analyzed by GC. The solid catalyst was separated from the liquid product by 30 min centrifugation followed by vacuum filtration. The filtrated liquid products were stored at $4^{\circ} \mathrm{C}$. The yield of gases was estimated as the difference of reactor weight with samples before and after each test. The yield of coke was calculated by subtracting the initial mass of catalyst added and the catalyst collected after filtering the oil and washing the catalyst with solvent. Finally, the yield of liquid was calculated by difference.

\section{Figure 1}

\section{Figure 2}

\subsection{Distillation}

A simple distillation setup (ASTM D86-12) was used. Briefly, a $20 \mathrm{~g}$ specimen was distilled in a laboratory batch distillation unit under ambient pressure. Systematic observations of temperature readings and mass of condensate are made. Hydrotreated liquid products were distilled to obtain the following fractions: $<71{ }^{\circ} \mathrm{C}$ (lights), $71-182^{\circ} \mathrm{C}$ (naphtha), $182-260^{\circ} \mathrm{C}$ (kerosene), $260-338^{\circ} \mathrm{C}$ (diesel), and $338-566^{\circ} \mathrm{C}$ (gas oil). A solid residue was collected from the distillation unit and its 
yield was reported as heavies [29]. Distillation for each sample is conducted in duplicate and the average yield is reported.

\subsection{Characterization on fresh and used $\mathrm{CoMo} / \mathrm{Al}_{2} \mathrm{O}_{3}$ catalysts}

Catalyst BET surface area and porosity was measured with micromeritics TriStar II PLUS (Norcross, GA, USA) using carbon dioxide and nitrogen adsorption isotherms at $273 \mathrm{~K}$ and 77.30 K respectively. Prior to each analysis samples were degassed at $200^{\circ} \mathrm{C}$ for $18 \mathrm{~h}$ under vacuum (0.1-5 mbar). $\mathrm{CO}_{2}$ adsorption isotherms were measured in the partial pressure range $\mathrm{p} / \mathrm{po}$ =10-5-0.03 using approximately 75 data points while nitrogen in a range of p/po 10-3-0.99. The micropore volumes were estimated for $\mathrm{CO}_{2}$ adsorption using the Dubin-Radushkevich (DR) equation. BET equation was used to estimate the surface area for nitrogen adsorption. Density functional theory (DFT) calculations were also carried out from $\mathrm{CO}_{2}$ adsorption isotherm using commercial software to calculate the micropore size distribution assuming a slit pore shape.

The topographic analysis of catalyst surface was carried out by scanning electron microscopy (SEM) with a Hitachi S-570 variable pressure instrumented. The samples were mounted on stub and later introduced into the instrument. Magnification ranged from 100X to 30,000X.

The composition of the catalyst was also measured by X-ray diffraction (XRD) using a Rikagu MiniFlex 600 benchtop X-ray defractometer. Diffraction spectra were collected between 5 and 50 degrees $2 \theta$ at a constant scan rate of 1 degree per minute. To ensure representative measurements the sampling pan was rotated during acquisition. 


\subsection{Gas Chromatography/ Mass Spectroscopy (GC-MS)}

The liquid products were analyzed by GC-MS using an Agilent Technologies 7890A GC set up (Agilent 19091S-433 HP-5MS column: $325^{\circ} \mathrm{C}: 30 \mathrm{~m}$ x $250 \mu \mathrm{m}$ x 0.25 $\mu \mathrm{m}$, Agilent 5975C MS with NIST 2.0 f Mass Spectral Search Program). Small samples were collected with a needle from the reaction mixture and 5 wt. \% blends with acetone were prepared for the GC-MS

analysis. The GC/MS analytical method used is as follows: Front inlet $\left(300{ }^{\circ} \mathrm{C}\right.$, total flow $\mathrm{He} 24$ $\mathrm{mL} / \mathrm{min}$, septum purge flow $3 \mathrm{~mL} / \mathrm{min}$; Split ratio 7:1, $20 \mathrm{~mL} / \mathrm{min})$. Column flow $(0.5 \mathrm{~mL} / \mathrm{min})$. Oven $\left(35^{\circ} \mathrm{C}\right.$ for $3 \mathrm{~min}$, ramp to 180 at $2{ }^{\circ} \mathrm{C} / \mathrm{min}$, ramp to 300 at $20{ }^{\circ} \mathrm{C} / \mathrm{min}$ and hold $3 \mathrm{~min}$. For quantifying the compounds, the system was calibrated with: benzene, toluene, n-octane, ethylbenzene, p-xylene, n-decane, naphthalene, n-dodecane, n-pentadecane, n-heptadecane and phenanthrene. The calibration was conducted with standards prepared at four different concentrations $(0.1,0.5,1$ and $5 \mathrm{mg} / \mathrm{g})$ using HPLC grade methanol as solvent.

\subsection{Gas Chromatography/Thermal Conductivity Detector (GC-TCD)}

The gases were collected in stainless steel collection cylinders of $150 \mathrm{ml}$ and analyzed for $\mathrm{H}_{2}$, $\mathrm{CH}_{4}, \mathrm{CO}, \mathrm{CO}_{2}$, ethane, propane and n-butane using a Varian CP-3800 Gas Chromatograph with a SilicaPLOT $50 \mathrm{~m} \times 0.53 \mathrm{~mm} \times 4 \mu \mathrm{m}$ column coupled with Thermal Conductivity (TCD), and Flame Ionization (FID) detectors. All gas samples were run in triplicates. The $\mathrm{H}_{2}, \mathrm{CH}_{4}$, $\mathrm{CO}$ and $\mathrm{CH}_{4}$ were measured using the $50 \mu \mathrm{l}$ injection loop, constant column flow of $8.0 \mathrm{ml} / \mathrm{min}$, and constant temperature $80^{\circ} \mathrm{C}$ held for $8 \mathrm{~min}$. The hydrocarbons, methane, ethane, propane and $\mathrm{n}$ - 
butane were analyzed with the Flame Ionization detector. For these hydrocarbons, $25 \mu 1$ injection loop was used, constant column flow of $8.0 \mathrm{ml} / \mathrm{min}$, and the following column oven temperature regime: $80^{\circ} \mathrm{C}$ hold for 2 minutes, ramp to $150{ }^{\circ} \mathrm{C}$ with $20^{\circ} \mathrm{C} / \mathrm{min}$ and hold for $8 \mathrm{~min}$, ramp to 190 ${ }^{\circ} \mathrm{C}$ with $30{ }^{\circ} \mathrm{C} / \mathrm{min}$ and hold for $3 \mathrm{~min}$, cool down to $80{ }^{\circ} \mathrm{C}$. Six standard gas mixtures with four known concentrations of $\mathrm{H}_{2}(0.1-99 \%), \mathrm{CO}(0.1-30 \%), \mathrm{CO}_{2}(0.1-33 \%), \mathrm{CH}_{4}(0.1-38 \%), \mathrm{C}_{2} \mathrm{H}_{6}$ (0.1-10\%), $\mathrm{C}_{3} \mathrm{H}_{8}(0.1-40 \%), \mathrm{n}-\mathrm{C}_{4} \mathrm{H}_{10}(0.1-10 \%)$ and $\mathrm{H}_{2} \mathrm{~S}(0.002-2 \%)$ were used for calibration. Samples were analyzed in triplicates and the averages reported.

\subsection{Gas Chromatography / Flame Ionization Detector (GC-FID)}

GC is equipped with a flame-ionization detector and a FAMEWAX column (30 m X $320 \mu \mathrm{m} \mathrm{X}$ $0.25 \mu \mathrm{m})\left(\right.$ Restek Corporation, Bellefonte, PA). The injector was kept at $260{ }^{\circ} \mathrm{C}$, with an injection volume of $1 \mu \mathrm{l}$ by split injection mode (ratio at 30:1). The initial oven temperature was set at $120{ }^{\circ} \mathrm{C}$, then increased at a heating rate of $3{ }^{\circ} \mathrm{C} / \mathrm{min}$ to $240{ }^{\circ} \mathrm{C}$ and held for $20 \mathrm{~min}$. The detector temperature was set at $250^{\circ} \mathrm{C}$. Helium was used as the carrier gas. Samples of size 30 $100 \mathrm{mg}$ canola oil were added in a test tube together with $5.3 \mathrm{ml}$ methanol, and $1 \mathrm{ml} \mathrm{of} 0.5 \mathrm{mg} / \mathrm{ml}$ tridecanoic acid as internal standard. In the test tube we added $0.58 \mathrm{ml}$ of $24 \mathrm{~N}$ sulfuric acid and close it tight with a cap, just before it was immersed in a $85^{\circ} \mathrm{C}$ water bath for 15 minutes. After cooling down the centrifuge tubes, $2 \mathrm{ml}$ of water was added, followed by $2 \mathrm{ml}$ of hexane, and mixed in a vortex vigorously for couple of minutes. The layers were then separated by centrifugation and the top hexane layer was injected in the GC-FID. The identification was accomplished by comparing the peak retention times of sample with the ones of FAME Mix from Sigma-Aldrich Co. This mix contains FAMEs ranging from C4:0 to C24:1, including most of the important saturated, monounsaturated, and polyunsaturated FAMEs. The detail composition of the FAME Mix can be found in references [30]. 


\subsection{Elemental Analysis}

Leco TruSpec CHN 628 series instrument was used to analyze all the liquid samples for carbon, hydrogen, and nitrogen content following ASTM D 5373-08 [31]. The oxygen content was calculated by difference. Biofuel sample of 0.10 gram was weighed into a tin foil cup, and then approximately 0.3 grams of Leco's Com-Aid was added on top and the foil cup was sealed by hand. Three point calibrations were done with LECO 502-092 EDTA.

\subsection{Total Acid Number (TAN)}

Mettler Toledo Automatic Titrator T50 with a DGi116-SC electrode was used following a modified ASTM-D664-11a method [31, 32]. Acetone was used as solvent instead of a mixture of toluene $(50 \%)$, isopropyl alcohol $(49.5 \%)$ and water $(0.5 \%) .0 .1 \mathrm{~N}$ potassium hydroxide in water (VWR AA35599-K7) was used instead of 0.1-N potassium hydroxide in isopropanol.

\subsection{Carbonyl content determination}

The content of carbonyl groups was determined with 2,4-dinitrophenylhydrazine (E411 2012) [32]. A series of standards using 2-butanone diluted in methanol was used for calibration. First a stock solution was prepared adding approximately $0.064 \mathrm{~g}$ of 2-butanone (Assay 99.8\%) to a 100 $\mathrm{mL}$ glass stoppered volumetric flask and completing the volume to the mark with methanol. 
Then a sequence of 2-10 mL aliquots of this stock solution was transferred to five $100 \mathrm{~mL}$ glass stoppered volumetric flasks and the volume completed with methanol. $2 \mathrm{~mL}$ aliquots of each standard were transferred to five $25 \mathrm{~mL}$ glass stoppered volumetric flasks. Additional $2 \mathrm{~mL}$ sample was transferred to others $25 \mathrm{~mL}$ volumetric flasks to be analyzed and $2 \mathrm{~mL}$ of methanol were transferred to another $25 \mathrm{~mL}$ volumetric flask to serve as blank. To each flask, $2 \mathrm{~mL}$ of 2,4dinitrophenylhydrazine was added for approximately 30 min before completing the volume with a 100g/L KOH solution and mixing well. The absorbance was measured using a Shimadzu UV2550PC UV/Vis Spectrophotometer at $480 \mathrm{~nm}$ after $12 \mathrm{~min}$. of adding the KOH solution.

\subsection{Fuel properties characterization}

Flash point: Pensky-Martens Closed Cup Flash Testers from Koehler was used in these studies. Due to the small sample quantities available, the initial instrument design was modified so it can accommodate testing according to ASTM D3278 - 96 (Standard Test Methods for Flash Point of Liquids by Small Scale Closed-Cup Apparatus). The testing was done on $2 \mathrm{ml}$ of liquid following the testing protocol described in ASTM D3278.

Kinematic Viscosity: It was measured with a Cannon Fenske glass tube viscometers immersed in a Koehler KV1000 bath. Three calibrated viscometers with 25, 50 and $100 \mathrm{~mL}$ were used. They are suitable for naphtha, kerosene, and diesel cut analysis, respectively. The whole test strictly followed the ASTM D445-15. 
Calorific Value: An IKA C200 Calorimeter was used. The instrument was calibrated by combusting two tablets of certified benzoic acid (IKA C 723, Lot SZBD2180V, gross cal. val $26461 \mathrm{~J} / \mathrm{g}$ ). The sample analysis was conducted using around $4 \mathrm{~g}$ of jet fuel and the pressure in the vessel was set to 30 bar (ASTM D4809 2013).

\section{Results and discussion}

\subsection{Tire and vegetable oils analysis}

GC-MS chromatograph of tire pyrolysis oil is shown in Figure 3. This oil was almost entirely composed of aromatics, in which benzene, toluene, xylene, and ethyl-benzene were the most abundant compounds. GC-FID was used to characterize the canola oil and the result shown in Figure 4. Palmitic acid methyl ester (C16:0), stearic acid methyl ester (C18:0), oleic acid methyl ester (C18:1), linoleic acid methyl ester (C18:2) and linoleic acid methyl ester (C18:3) were the major FAMEs characterized from canola oil. This implies that triglycerides in canola oil are mainly composed of C18 monounsaturaed fatty acid although saturated C16 and C18 were identified as well.

\section{Figure 3}

\section{Figure 4}




\subsection{Analysis of catalyst}

\subsubsection{BET surface}

Catalyst surface area and pore volumes before and after the cohydrotreatment experiments are listed in Table 1. The largest surface area was observed for the fresh catalyst $\left(234 \mathrm{~m}^{2} / \mathrm{g}\right)$. This surface area is similar $\left(212 \mathrm{~m}^{2} / \mathrm{g}\right)$ to the one reported for a similar catalyst by Wu et al [34]. The surface area decreased for all used catalysts likely due to pore blocking. Although the overall surface area does not change much, the vegetable oil seems to block mostly micropores and the tire oil mesopores. With increasing the tire ratio in the blends, the micropore volume increased while mesopore volume decreased.

\section{Table 1.}

\subsubsection{SEM}

The SEM micrographs on fresh and used $\mathrm{CoMo} / \mathrm{Al}_{2} \mathrm{O}_{3}$ are shown in Figure 5. The Co and Mo oxides can be observed in white crystallized structures from the Figure 5-(a). For used catalysts, although coke formation on the support or metal particles cannot be clearly observed, agglomeration of Co and/or Mo oxides indeed occur to some extent as comparing with the fresh catalyst [35] (see Figure 5-b-f). With increasing the tire ratio in the blends, however, the expected tendency of increasing pore blocking was not confirmed. 


\section{Figure 5.}

\subsubsection{XRD}

XRD was used to further analyze catalyst chemistry. Results are shown in Figure 6. The most prominent peaks at 46 and $67^{\circ}$ are associated to $\gamma-\mathrm{Al}_{2} \mathrm{O}_{3}$. This peak can be observed in fresh and used catalysts. The peak associated from $\mathrm{Co}_{3} \mathrm{O}_{4}$ diffraction was detected for all catalysts. No detectable XRD diffraction peaks of any $\mathrm{MoO}_{3}$ species were observed, indicating that their crystals are probably smaller than $4 \mathrm{~nm}$ [36]. The characteristic diffraction peaks of $\mathrm{MoS}_{2}$ occur at 34 and $58^{\circ}[28,36]$. The spent catalysts with $\mathrm{MoS}_{2}$ peaks are those resulting from hydrotreatments in which tire oil was present. Tire oil sulfur favored the regeneration of $\mathrm{MoS}_{2}$.

\section{Figure 6.}

\subsection{Co-hydrotreatment pressure profiles}

Figure 7 shows pressure profiles for each of the co-hydrotreatment tests. The starting point for each of the profiles was $25^{\circ} \mathrm{C}$ and $1,325 \mathrm{psi}(9.1 \mathrm{MPa})$. By analyzing hydrotreatment pressure profiles, the most predominant reaction can be studied. Some of the reactions happening during co-hydrotreatment and that could have an impact in the pressure profile are: 1) hydrogenation of unsaturated carbon-carbon double bonds on the backbone of triglycerides from vegetable oil, 2) hydrogenation of aromatics/poly-aromatics from tire oil, 3) hydrocracking of hydrocarbon chains in triglycerides, and 4) decarboxylation/decarbonylation of triglycerides. $\mathrm{H}_{2}$ consumption will 
likely result in an observable pressure drop. The pressure will increase from either hydrocracking or decarboxylation/decarbonylation reactions. In Figure 7 it can be observed that the pressure for all the reactions kept increasing until temperature reached $350^{\circ} \mathrm{C}$. Comparing with the pure tire oil, hydrotreatment of pure canola oil have higher pressure at $350{ }^{\circ} \mathrm{C}$ likely associated with the production of carbon dioxide, carbon monoxide and aliphatic hydrocarbons with shorter chain produced through decarboxylation/decarbonylation and hydrocracking of triglycerides in vegetable oil, respectively. On the other hand, hydrogenation was not dominant reaction in the heating-up stage but started to prevail slowly after the temperature stabilized at $350{ }^{\circ} \mathrm{C}$. This trend was extremely obvious when there are more tire oil in the feed, implying that hydrogenation of aromatics consumed a large amount of $\mathrm{H}_{2}$ once the temperature is high enough.

\section{Figure 7.}

\subsection{Yield of products and analysis of gases}

Figure 8 shows the yield of products. Liquid product yield was close to $90 \mathrm{wt} \%$ and coke yield was lower than 1.42 wt. \% for all the blends studied. No wax was formed in any of the tests. With increasing tire oil content, the liquid yield increased and the gas yield decreased. The yield of gases increased with the content of vegetable oil. Only minor amount coke was formed when canola oil was hydrotreated.

Gaseous products were mostly produced from hydrocracking and decarboxylation/decarbonylation of vegetable oil. As evidenced by GC analysis, carbon dioxide 
$\left(\mathrm{CO}_{2}\right)$, carbon monoxide $(\mathrm{CO})$, and methane $\left(\mathrm{CH}_{4}\right)$ were the major gaseous products although minor amount of ethane $\left(\mathrm{C}_{2} \mathrm{H}_{6}\right)$, propane $\left(\mathrm{C}_{3} \mathrm{H}_{8}\right)$, and butane $\left(\mathrm{C}_{4} \mathrm{H}_{10}\right)$ were also detected (Table 2). $\mathrm{CO}_{2}$ is mostly formed from vegetable oil. With the increase in tire oil content $\mathrm{CO}_{2}$ concentration decreased and $\mathrm{CO}$ and $\mathrm{CH}_{4}$ increased.

\section{Figure 8.}

\section{Table 2}

\subsection{Liquid product characterization:}

The liquid products of vegetable oil/tires oil co-hydrotreatment were analyzed by GC-MS. The major compounds identified are shown in Figure 9 and Table 3. The major liquid products from pure canola oil hydrotreatment were a series of aliphatic hydrocarbons with carbon number from C7 to C20. For pure tire oil, there were no new compounds identified after hydrotreatment. The intensity of each peak assigned for compound increased as comparing Figure 3 and Figure 9(e). This possibly reveals the hydrocracking of $\mathrm{C}-\mathrm{C}$ bonds in raw tire oil to free smaller aromatics, such as from methyl-biphenyl to toluene and benzene. In addition, from the tires oil we see the formation of methyl cyclohexane, ethyl cyclohexane, 1,2,3-trimethyl-benzene, 1methyl-4-(1-methylethyl)-cyclohexane. These are basically products of ring hydrogenation.

\section{Figure 9}


The major compounds from Table 3 were then selected for further quantification with external standards. These compounds included all liquid aliphatic hydrocarbons produced from C7 to C20 and several important aromatic hydrocarbons such as benzene, ethyl-benzene, toluene, naphthalene, and others. The differences in the composition of tires oil and the hydrotreated oils can be observed when comparing the column for tires oil and the column for 0:100 (product of tires oil hydrotreatment). The differences in composition between the vegetable oil and the hydrotreated vegetable oil can be observed when comparing the free fatty acids shown in Figure 3 and the aliphatic compounds shown in Table 3.From the tires oil we see the formation of methyl cyclohexane, ethyl cyclohexane, 1,2,3-trimethyl-benzene, 1-methyl-4-(1-methylethyl)cyclohexane. These are basically products of ring hydrogenation. The main products detected from the vegetable oil were aliphatic hydrocarbons (n-heptane, n-octane, n-nonane, n-decane, nundecane, n-dodecane, n-tridecane, n-tretradecane.).The concentrations of all the selected compounds were calculated and the relationship between the concentrations and canola/tire oil weight ratio is shown in Figure 10.

\section{Table 3.}

The most abundant two compounds from vegetable oil were n-heptadecane (C17) and noctadecane (C18) (see Figure 10-(a)). This result implied that hydrogenation of $\mathrm{C}=\mathrm{C}$ bond predominantly occurred as well as hydrocracking of C18 to C17 during hydrotreatment of vegetable oil. Alumina in the catalyst of $\mathrm{CoMo} / \mathrm{Al}_{2} \mathrm{O}_{3}$ has moderate acidic sites critical for hydrocracking reactions. However, the aliphatic hydrocarbons, especially C17 and C18 dramatically decreased when 20 wt. \% tires oil was added. This demonstrates that the addition of tire oil may have accelerated the hydrocracking of canola oil. On the other hand, as shown in 
Figure 10-(b), the increase of tire oil in the blends contributed to the increase of aromatic content. The content of aromatics increased linearly as the tires oil was added suggesting limited synergistic effects.

\section{Figure 10}

The difference in elemental composition before and after hydrotreatment can also be observed in Table 4. The hydrogen content of canola oil was 77.1 wt. \%. The hydrotreated oil contained 83.9 wt. \%. The oxygen content decreased from 11.5 to 3.2 wt. $\%$, demonstrating an effective deoxygenation during hydrotreatment. In the case of tires oil the carbon and hydrogen content increased slightly ( $\mathrm{C}$ from 85.8 to 86.4 wt. $\%$ and $\mathrm{H}$ from 8.7 to 9.3 ). The nitrogen content also decreased (from 0.6 to 0.2 wt. \%). More importantly, the sulfur content decreased dramatically (from 1.12 to 0.22 wt.\%). With increasing the portion of tire oil in the blends for cohydrotreatment, carbon and sulfur content increases, and the oxygen and hydrogen content decreases.

\section{Table 3}

Table 5 shows the total acid number (TAN) of the feedstock and all the hydrotreated oils. There was no acids identified from the primitive canola oil while the raw tire oil contained relatively high TAN (8.5 mg KOH/g oil). Nevertheless, the one that gave the highest TAN is hydrotreated canola oil (10.5 mg KOH/g oil). This is probably due to the presence of minor amount of free fatty acid in the liquid product. Inversely, an obvious decrease of TAN can be observed after 
hydrotreating tire oil. For the cohydrotreatment of blends, the TAN of hydrotreated oils decreased with the increase of initial tire oil ratio in the feed since acids can be effectively removed in tire oil hydrotreatment. To note, the canola oil derived free fatty acid can be also further removed by extending the reaction time, which will then decrease the TAN of resulting oils.The result reveals that co-hydrotreating canola oil with tire oil can also lower the total acid number of hydrotreated oil, which is an important parameter for storage and processability of the fuel in the standard refineries.

\section{Table 4}

\subsection{Distillation of hydrotreated oil}

Distillation of tire oil and hydrotreated oils was conducted and five cuts were separated and collected for further analysis. The yield for each cut was calculated and listed in Table $\mathbf{6}$. The raw tire oil was isolated into four cuts after distillation, and a residue. The naphtha cut represented $30 \mathrm{wt} . \%$, the kerosene $18 \mathrm{wt} . \%$, diesel $20 \mathrm{wt} . \%$ and gas oil $10 \mathrm{wt} . \%$. However, there was 16.27 wt. \% collected as residue mostly derived from the polyaromatics. Diesel cuts were the major fraction in the liquid products over $\mathrm{CoMo} / \mathrm{Al}_{2} \mathrm{O}_{3}$. In the case of hydrotreated canola oil, the catalyst favored cracking into naphtha (13.4 wt.\%), kerosene (17.6 wt.\%), and diesel (60.2 wt.\%) with 2.7 wt. \% residue. By increasing the tire oil portion in the blends, the yield of naphtha increased. This is because small aromatics in tire oil contribute more towards the naphtha cut, and hydrocracked triglycerides are mostly responsible for the diesel cut. The yield of diesel decreased when canola oil was gradually replaced by tire oil. However, there is no obvious trend for the kerosene cut. 
The GC/MS chromatograph of cuts obtained from hydrotreated Canola oil, tire and their 50/50 blends are shown in Figures 11, 12 and 13. The naphtha cut of hydrotreated pure canola oil were mainly composed of aliphatic hydrocarbons with carbon number ranged from C7 to C12. Compounds from kerosene cut are aliphatics with carbon numbers in between C9 and C18. The diesel cut mainly contained aliphatics with carbon number ranged from 15 to 20 . On the other hand, naphtha, kerosene, and diesel cuts of tire oil mainly contained aromatics from C6 to C10, C7 to $\mathrm{C} 14$, and $\mathrm{C} 10$ to $\mathrm{C} 16$, respectively. The cuts of hydrotreated oils from blends of tire and canola oil contained both aliphatics and aromatics.

\section{Table 5}

\section{Figure 2}

\section{Figure 3}

\section{Figure 4}

Figure 14 shows the elemental analysis results of each of the fractions obtained. For all the distillation cuts, carbon content increased as tire oil was added to the blend. The hydrogen and oxygen contents decreased with the increase of tire oil portion in the blends.

\section{Figure 5}


Some of the fuel properties of the cuts obtained are shown in Table 7-9. As shown in Table 7, flash point of canola oil was determined as $275^{\circ} \mathrm{C}$, which was similar with Przybylski's result [37] However, the primitive blends had flash points lower than $20^{\circ} \mathrm{C}$ (determination lower limit)unless decreasing the tire oil ratio to $20 \mathrm{wt} . \%$ as shown in Table $7\left(\right.$ canola- $\left.80: 36^{\circ} \mathrm{C}\right)$. This is because the raw tire oil contained many volatile aromatics and therefore made the flash point easily to be reached. Nevertheless, the flash points of the resulting kerosene cuts ranged from 40 to $51^{\circ} \mathrm{C}$, which matched perfectly with the commercial jet fuel $\left(>38^{\circ} \mathrm{C}\right)$. For all diesel cuts, the flash points varied between 49 and $56^{\circ} \mathrm{C}$, which are also comparable with the conventional diesel fuels (Table 7). On the other hand, kinematic viscosity was also conducted at $40{ }^{\circ} \mathrm{C}$ for all the feed and resulting distillation cuts. Conventional No.2 diesel in United State has the kinematic viscosity at $40{ }^{\circ} \mathrm{C}$ ranged from 1.9 to $4.1 \mathrm{~mm}^{2} / \mathrm{s}$ [38]. In this study, the kinematic viscosity ranged from 3.743 to $36.351 \mathrm{~mm}^{2} / \mathrm{s}$ for the all the feed with highest one from pure canola oil as listed in Table 8. For the distillation cuts in this study, the kinematic viscosity of the diesel cuts ranged from 3.5 to $6.8 \mathrm{~mm}^{2} / \mathrm{s}$, which are similar with the commercial diesel fuels (Table 8). The kinematic viscosity of naphtha cuts were all lower than $1 \mathrm{~mm}^{2} / \mathrm{s}$ and the corresponding value for kerosene cuts varied from 1.6 to $2.15 \mathrm{~mm}^{2} / \mathrm{s}$. These values from distillation cuts were all very comparable with the commercial fuels. In addition, the carbonyl content determination for all cuts were conducted and the results were listed in Table 9. Carbonyl content were all below $0.1 \%$, which is comparable with other alternative jet fuels. In the feed, raw tire oil contained the highest level of carbonyl while canola oil had the lowest. After cohydrotreatment, the highest content of carbonyl groups were obtained in canola oil derived cuts instead due to the incomplete decarbonylation. Carbonyl content for all the cuts decreased as the content of tire oil increased. 


\section{Table 7}

\section{Table 8}

Table 9

The calorific heating values for all distillation cuts were shown in Figure 15. With the decrease of canola oil in the feedstock, the heating values of the distillation cuts decreased correspondingly due to the reducing concentrations of aliphatic hydrocarbons. The heating value is determined by the elemental composition of the fuel $(\mathrm{C}, \mathrm{H}$, and $\mathrm{O})$. Regardless of the canola/tire oil ratio, the kerosene cut was always the most energy-dense fuel. Heating values of diesel cuts were slightly lower than the ones of kerosene cuts for cohydrotreated oils but decreases for tires derived cut.

\section{Figure 6}

\section{Conclusions}

The co-hydrotreatment of tires oil and vegetable oil in installations developed for the production of green diesel seems to be a viable approach to take advantage of existing infrastructure for the processing of tires oil. Tire oil is an excellent source of naphthenics and aromatics. The yield of hydrotreated oils was very high (above $90 \mathrm{wt} . \%$ ) with very low yields of coke. A small decrease in surface area due to the blockage of some pores was observed when used catalysts were analyzed. Naphtha, kerosene, and diesel cuts were isolated from the co-hydrocracked oils by simple distillation. Aliphatic C7-C12 and aromatic C6-C10 were mainly collected in the naphtha cut, aliphatic C9-C18 and aromatic C7-C14 in the kerosene cut, and aliphatic C15-C20 and aromatic $\mathrm{C} 10-\mathrm{C} 16$ went to the diesel cut. For all the distillation cuts, carbon content increased, 
and hydrogen and oxygen contents decreased with the increase of tire oil portion in the blends. The produced distillation cuts had comparable $\mathrm{H} / \mathrm{C}$ ratios, flash points and kinematic viscosity to conventional petroleum fuels.

\section{Acknowledgements:}

Filip Stankobikj wants to thank Fulbright S\&T for providing scholarship, Jonathan Lomber within the Analytical Chemistry Service Center at Biological Systems Engineering Department for providing instrumentation and technical support. Financial support from the Joint Center for Aerospace Technology Innovation, the Boeing Company and Conrad Industries for this research are gratefully acknowledged. Dr. Garcia-Perez is very thankful for the financial support provided by the US National Science Foundation (CBET-1434073, CAREER CBET-1150430). This project was also partially funded by the USDA/NIFA through Hatch Projects \# WNP00701.

\section{References}

[1] I.A.T. Association, IATA 2013 Report on Alternative Fuels, 2013, pp. 78.

[2] T. Morgan, E. Santillan-Jimenez, A.E. Harman-Ware, Y. Ji, D. Grubb, M. Crocker, Catalytic deoxygenation of triglycerides to hydrocarbons over supported nickel catalysts, Chemical Engineering Journal, 189-190 (2012) 346-355.

[3] S. Liu, Q. Zhu, Q. Guan, L. He, W. Li, Bio-aviation fuel production from hydroprocessing castor oil promoted by the nickel-based bifunctional catalysts, Bioresource technology, 183 (2015) 93-100.

[4] A.F.H. Studentschnig, S. Schober, M. Mittelbach, Conversion of Crude Palm Oil into Hydrocarbons over Commercial Raney Nickel, Energy \& Fuels, 27 (2013) 7480-7484. 
[5] D. Kubička, L. Kaluža, Deoxygenation of vegetable oils over sulfided Ni, Mo and NiMo catalysts, Applied Catalysis A: General, 372 (2010) 199-208.

[6] D. Verma, B.S. Rana, R. Kumar, M.G. Sibi, A.K. Sinha, Diesel and aviation kerosene with desired aromatics from hydroprocessing of jatropha oil over hydrogenation catalysts supported on hierarchical mesoporous SAPO-11, Applied Catalysis A: General, 490 (2015) 108-116.

[7] S. Kovács, T. Kasza, A. Thernesz, I.W. Horváth, J. Hancsók, Fuel production by hydrotreating of triglycerides on NiMo/Al2O3/F catalyst, Chemical Engineering Journal, 176-177 (2011) 237-243.

[8] H. Wang, S. Yan, S.O. Salley, K.Y.S. Ng, Hydrocarbon Fuels Production from Hydrocracking of Soybean Oil Using Transition Metal Carbides and Nitrides Supported on ZSM-5, Industrial \& Engineering Chemistry Research, 51 (2012) 10066-10073.

[9] M.S.E. S.A. Hanafi, H.A. El-Syed and Nasser H. Shalaby, Hydrocracking of waste cooking oil as renewable fuel on NiW-SilicaAlumina catalyst, Journal of Advanced Catalysis Science and Technology, 2 (2015) 27-37.

[10] M. Snåre, I. Kubičková, P. Mäki-Arvela, K. Eränen, J. Wärnå, D.Y. Murzin, Production of diesel fuel from renewable feeds: Kinetics of ethyl stearate decarboxylation, Chemical Engineering Journal, 134 (2007) 29-34.

[11] J.-G. Na, B.E. Yi, J.K. Han, Y.-K. Oh, J.-H. Park, T.S. Jung, S.S. Han, H.C. Yoon, J.-N. Kim, H. Lee, C.H. Ko, Deoxygenation of microalgal oil into hydrocarbon with precious metal catalysts: Optimization of reaction conditions and supports, Energy, 47 (2012) 25-30.

[12] a.X.L.a.P.E.S. Jie Fu, Catalytic hydrothermal deoxygenation of palmitic acid, Energy \& Environmental Science, 3 (2010) 311-317.

[13] P. Mäki-Arvela, M. Snåre, K. Eränen, J. Myllyoja, D.Y. Murzin, Continuous decarboxylation of lauric acid over Pd/C catalyst, Fuel, 87 (2008) 3543-3549.

[14] S. Bezergianni, A. Kalogianni, A. Dimitriadis, Catalyst evaluation for waste cooking oil hydroprocessing, Fuel, 93 (2012) 638-641.

[15] W. Kiatkittipong, S. Phimsen, K. Kiatkittipong, S. Wongsakulphasatch, N. Laosiripojana, S. Assabumrungrat, Diesel-like hydrocarbon production from hydroprocessing of relevant refining palm oil, Fuel Processing Technology, 116 (2013) 16-26. 
[16] S. Gong, N. Chen, S. Nakayama, E.W. Qian, Isomerization of n-alkanes derived from jatropha oil over bifunctional catalysts, Journal of Molecular Catalysis A: Chemical, 370 (2013) 14-21.

[17] A. Srifa, K. Faungnawakij, V. Itthibenchapong, N. Viriya-Empikul, T. Charinpanitkul, S. Assabumrungrat, Production of bio-hydrogenated diesel by catalytic hydrotreating of palm oil over NiMoS2/gamma-Al2O3 catalyst, Bioresource technology, 158 (2014) 81-90.

[18] E. Santillan-Jimenez, T. Morgan, J. Lacny, S. Mohapatra, M. Crocker, Catalytic deoxygenation of triglycerides and fatty acids to hydrocarbons over carbon-supported nickel, Fuel, 103 (2013) 1010-1017.

[19] Q. Liu, H. Zuo, T. Wang, L. Ma, Q. Zhang, One-step hydrodeoxygenation of palm oil to isomerized hydrocarbon fuels over Ni supported on nano-sized SAPO-11 catalysts, Applied Catalysis A: General, 468 (2013) 68-74.

[20] H. Wang, S. Yan, S.O. Salley, K.Y. Simon Ng, Support effects on hydrotreating of soybean oil over NiMo carbide catalyst, Fuel, 111 (2013) 81-87.

[21] R. Tiwari, B.S. Rana, R. Kumar, D. Verma, R. Kumar, R.K. Joshi, M.O. Garg, A.K. Sinha, Hydrotreating and hydrocracking catalysts for processing of waste soya-oil and refinery-oil mixtures, Catalysis Communications, 12 (2011) 559-562.

[22] S. Parmar, K.K. Pant, M. John, K. Kumar, S.M. Pai, B.L. Newalkar, Hydroisomerization of Long Chainn-Paraffins over Pt/ZSM-22: Influence of Si/Al Ratio, Energy \& Fuels, (2015) 150209070048005.

[23] M. Ahmadi, E.E. Macias, J.B. Jasinski, P. Ratnasamy, M.A. Carreon, Decarboxylation and further transformation of oleic acid over bifunctional, Pt/SAPO-11 catalyst and Pt/chloride Al2O3 catalysts, Journal of Molecular Catalysis A: Chemical, 386 (2014) 14-19.

[24] M. Herskowitz, M.V. Landau, Y. Reizner, D. Berger, A commercially-viable, one-step process for production of green diesel from soybean oil on Pt/SAPO-11, Fuel, 111 (2013) 157-164.

[25] M. Anand, A.K. Sinha, Temperature-dependent reaction pathways for the anomalous hydrocracking of triglycerides in the presence of sulfided Co-Mo-catalyst, Bioresource technology, 126 (2012) 148-155. 
[26] S.K. Kim, S. Brand, H.-s. Lee, Y. Kim, J. Kim, Production of renewable diesel by hydrotreatment of soybean oil: Effect of reaction parameters, Chemical Engineering Journal, 228 (2013) 114-123.

[27] I. Hita, A. Gutiérrez, M. Olazar, J. Bilbao, J.M. Arandes, P. Castaño, Upgrading model compounds and Scrap Tires Pyrolysis Oil (STPO) on hydrotreating NiMo catalysts with tailored supports, Fuel, 145 (2015) 158-169.

[28] M. Krar, S. Kovacs, D. Kallo, J. Hancsok, Fuel purpose hydrotreating of sunflower oil on CoMo/Al2O3 catalyst, Bioresource technology, 101 (2010) 9287-9293.

[29] E.D. Christensen, G.M. Chupka, J. Luecke, T. Smurthwaite, T.L. Alleman, K. Iisa, J.A. Franz, D.C. Elliott, R.L. McCormick, Analysis of Oxygenated Compounds in Hydrotreated Biomass Fast Pyrolysis Oil Distillate Fractions, Energy \& Fuels, 25 (2011) 5462-5471.

[30] Supelco, Comparison of 37 Component FAME Standard on Four Capillary GC Columns, in: Sigma-Aldrich (Ed.) T100907, Sigma-Aldrich, 1996.

[31] M.R. Pelaez-Samaniego, V. Yadama, M. Garcia-Perez, E. Lowell, A.G. McDonald, Effect of temperature during wood torrefaction on the formation of lignin liquid intermediates. Journal of Analytical and Applied Pyrolysis, 109, (2014) 222-233

[32] ASTM, D664 - 11a, Standard Test Method for Acid Number of Petroleum Products by Potentiometric Titration, ASTM International, 2011.

[33] F. Stankovikj, A.G. McDonald, G.L. Helms, M. Garcia-Perez; Quantification of Bio-oil Functional Groups and Evidences of the Presence of Pyrolytic Humins, Energy \& Fuels, 2016, 30 (8), 6505-6524

[34] L.B. Wu, D.M. Jiao, L.F. Chen, J.A. Wang, F.H. Cao, Comparative Studies of the $\mathrm{CoMo} / \mathrm{MgO}, \mathrm{CoMo} / \mathrm{Al} 2 \mathrm{O} 3$ and $\mathrm{CoMo} / \mathrm{MgO}-\mathrm{MgAl} 2 \mathrm{O} 4$ Catalysts Prepared by a UreaMatrix Combustion Method, Advanced Materials Research, 132 (2010) 45-54.

[35] H. Zhang, H. Lin, Y. Zheng, The role of cobalt and nickel in deoxygenation of vegetable oils, Applied Catalysis B: Environmental, 160-161 (2014) 415-422.

[36] Y. Wang, H. Lin, Y. Zheng, Hydrotreatment of lignocellulosic biomass derived oil using a sulfided NiMo/ $\gamma$-Al2O3catalyst, Catalysis Science \& Technology, 4 (2014) 109-119.

[37] R.P. Frank D. Gunstone, Canola/Rapeseed Oil, in Vegetable Oils in Food Technology: Composition,Properties and Uses, Wiley-Blackwell, Oxford, UK. , 2011. 
[38] G. Knothe, K.R. Steidley, Kinematic viscosity of biodiesel fuel components and related compounds. Influence of compound structure and comparison to petrodiesel fuel components, Fuel, 84 (2005) 1059-1065. 


\section{List of Figures}

Figure 1. Experimental workflow of co-hydrotreatment of tire pyrolysis oil and canola oil

Figure 2. Experimental set up and typical hydrotreatment conditions

Figure 3. GC-MS characterization on raw pyrolysis tire oil

Figure 4. GC-FID characterization on canola oil

Figure 5. SEM micrographs for fresh and used catalysts

Figure 6. XRD analysis on fresh and used catalysts

Figure 7. Pressure profiles during cohydrotreatment

Figure 8. Product yields for the co-hydrotreatment of tire oil and canola oil

Figure 9. GC-MS characterization on liquid products from co-hydrotreatment

Figure 10 Yield of targeted compounds

Figure 11. GC-MS of distillation cuts from hydrotreated canola

Figure 12. GC-MS of distillation cuts from hydrotreated canola-tires oil (50/50)

Figure 13. GC-MS on distillation cuts from hydrotreated tire oil

Figure 14. Elemental analysis for distillation cuts from hydrotreated oil

Figure 15. Calorific heating value of produced distillation cuts 


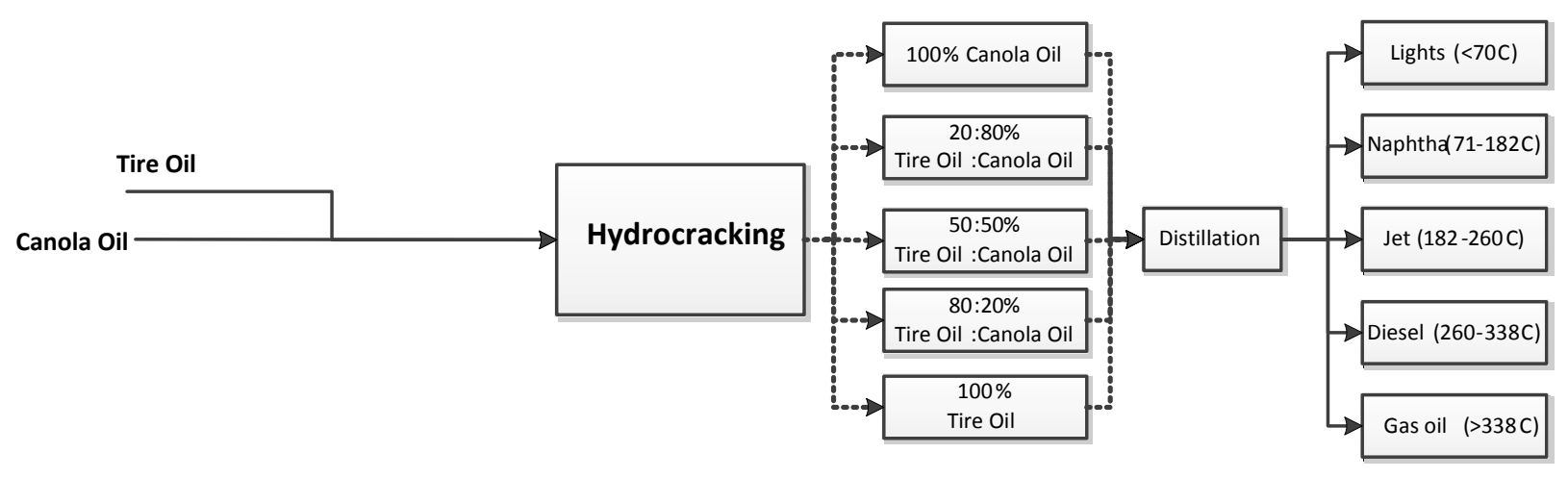

Figure 1. Experimental workflow of co-hydrotreatment of tire pyrolysis oil and canola oil 


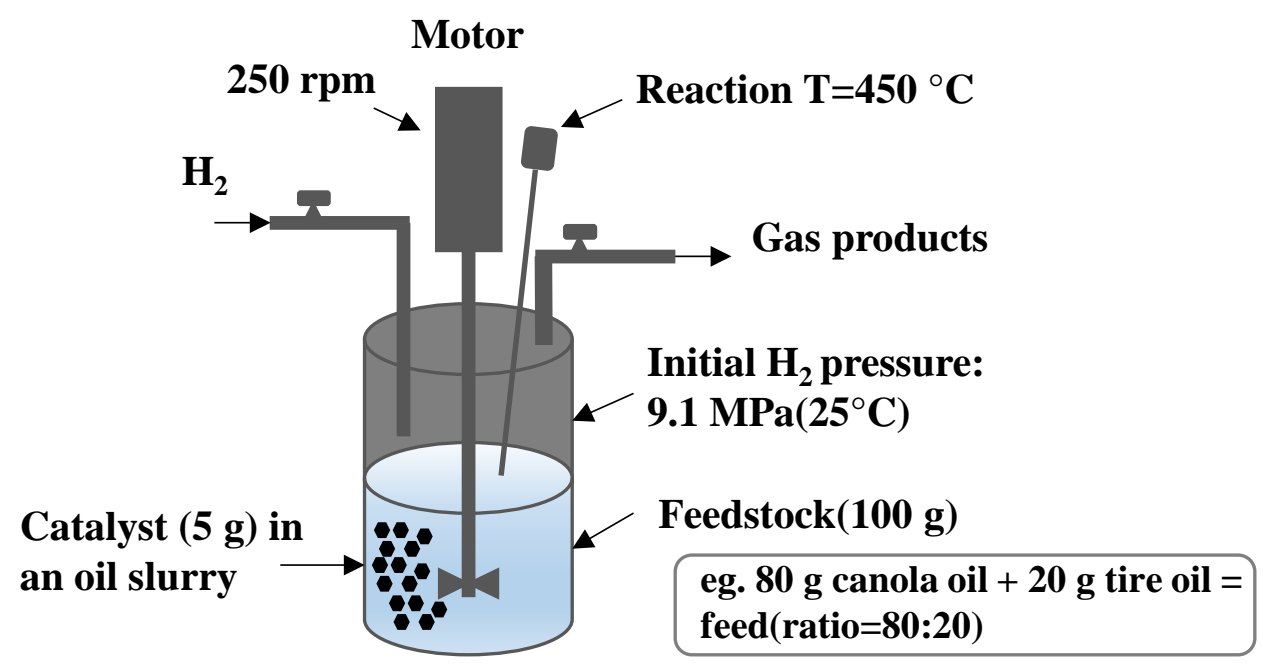

Reactor capacity: $250 \mathrm{~mL}$

Reaction time : 4 hours

Figure 2. Experimental set up and typical hydrotreatment conditions 


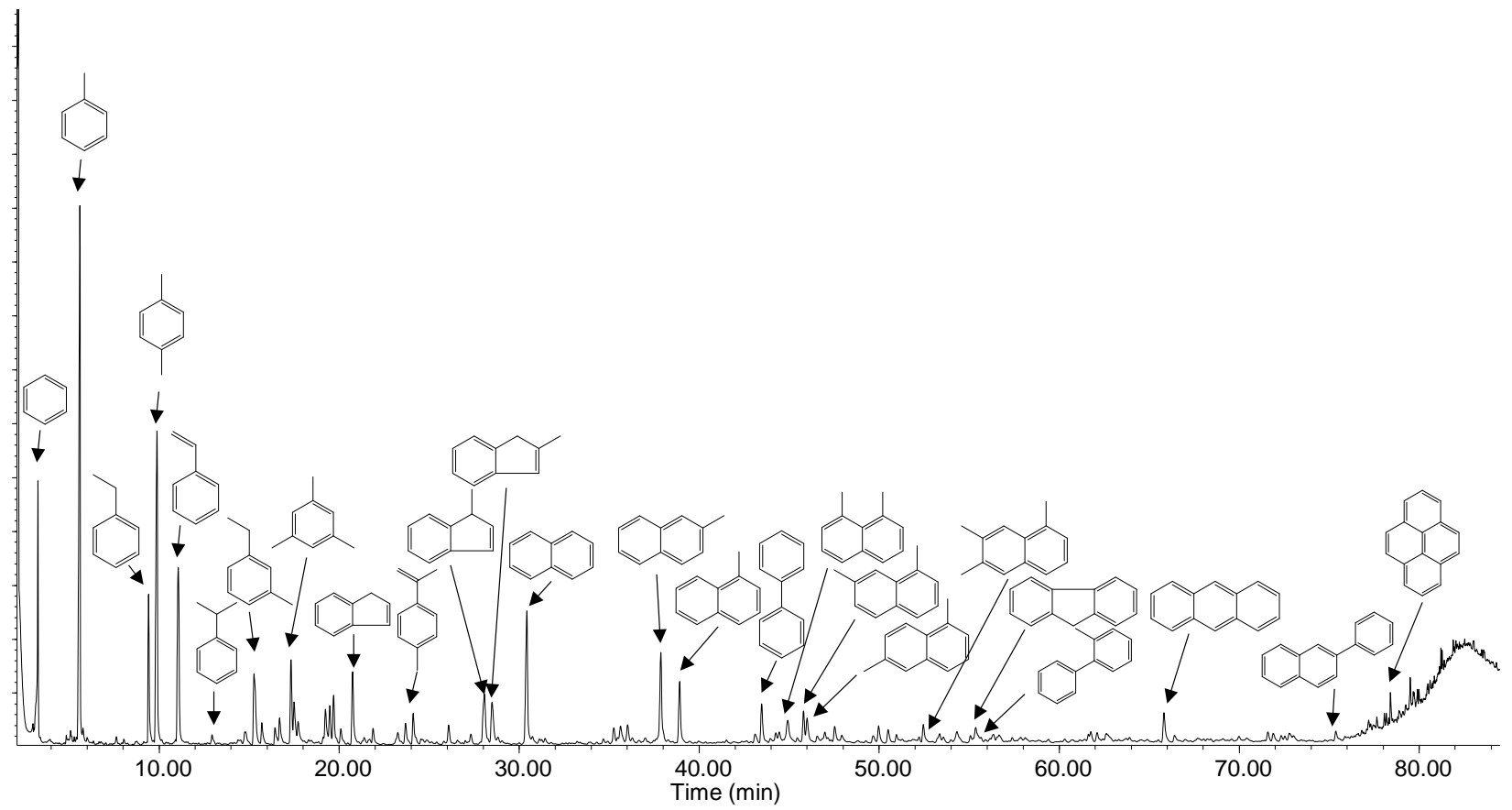

Figure 3. GC-MS characterization on raw pyrolysis tire oil 


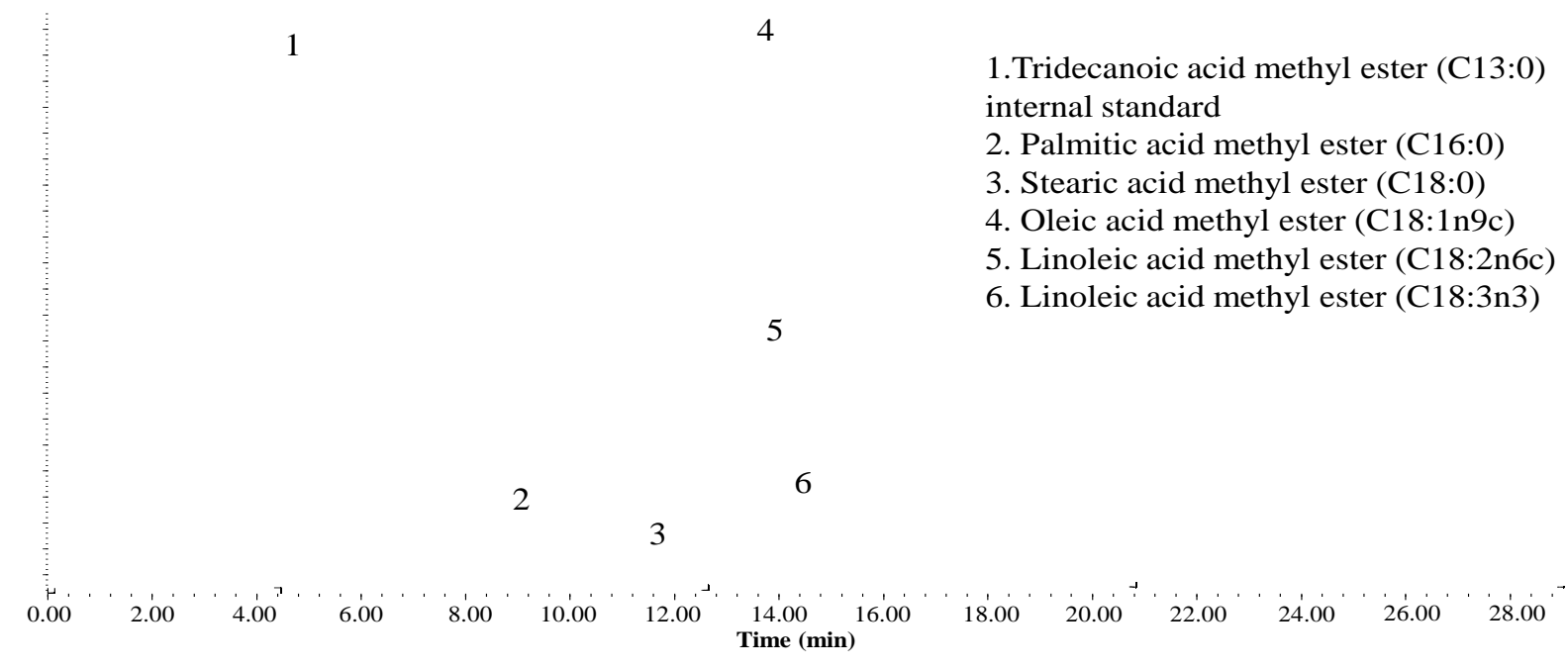

Figure 4. GC-FID characterization on canola oil 

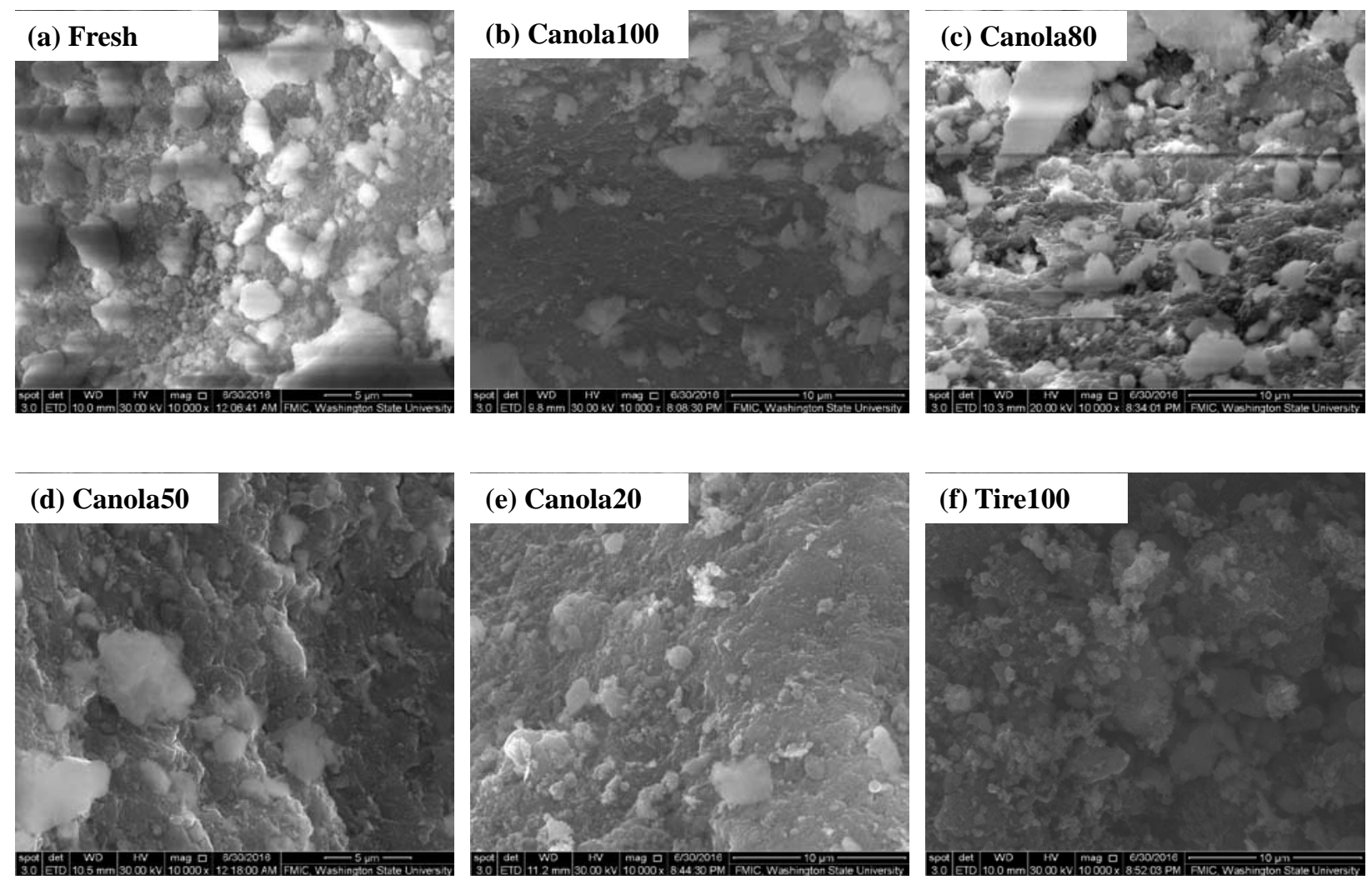

Figure 5. $\mathrm{SEM}$ micrographs for fresh and used $\mathrm{CoMo} / \mathrm{Al}_{2} \mathrm{O}_{3}$ catalysts 


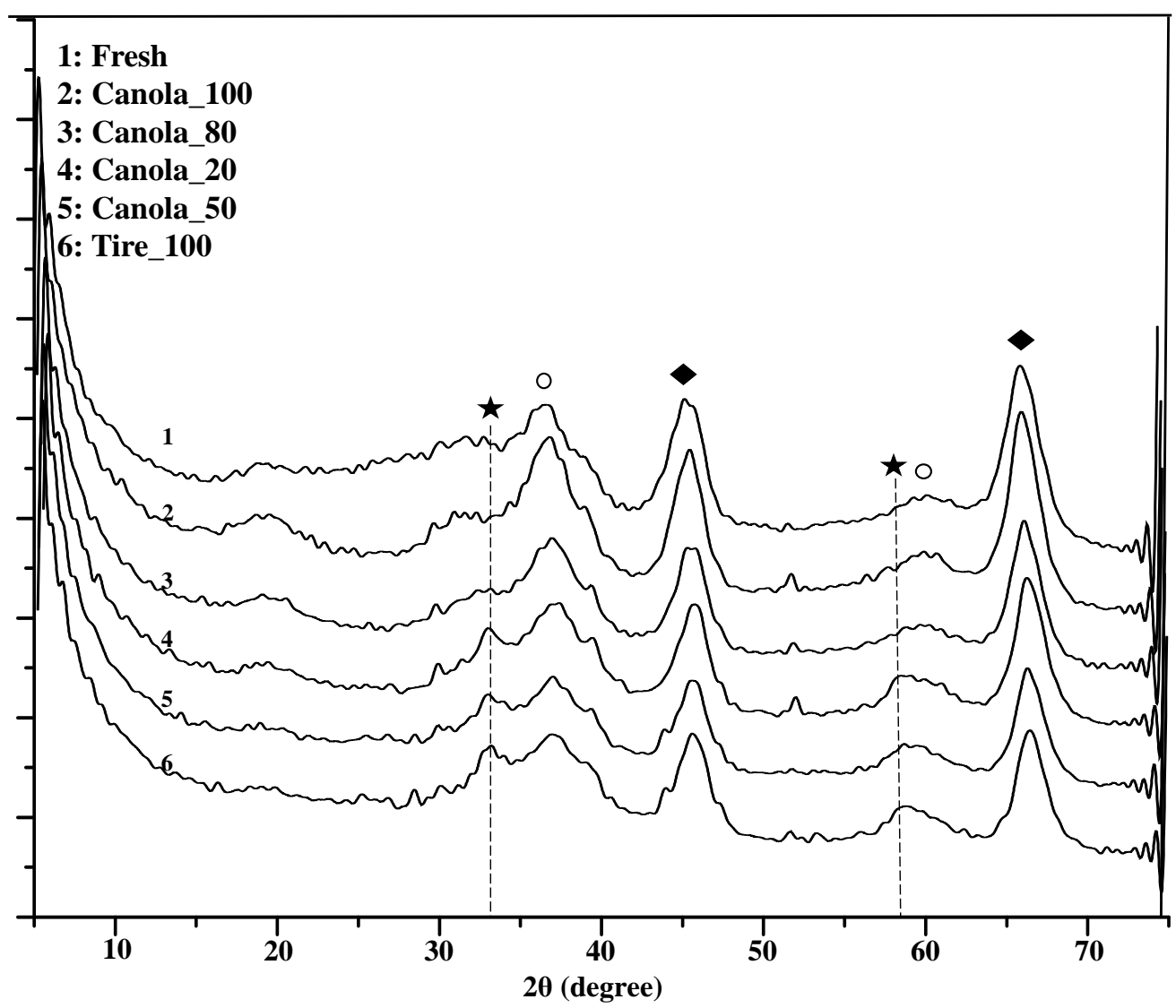

Figure 6. XRD analysis on fresh and used $\mathrm{CoMo} / \mathrm{Al}_{2} \mathrm{O}_{3}$ catalysts, $\bullet-\gamma-\mathrm{Al}_{2} \mathrm{O}_{3}, \mathrm{O}-\mathrm{Co}_{3} \mathrm{O}_{4}$, $\star-$ $\mathrm{MoS}_{2}$ 


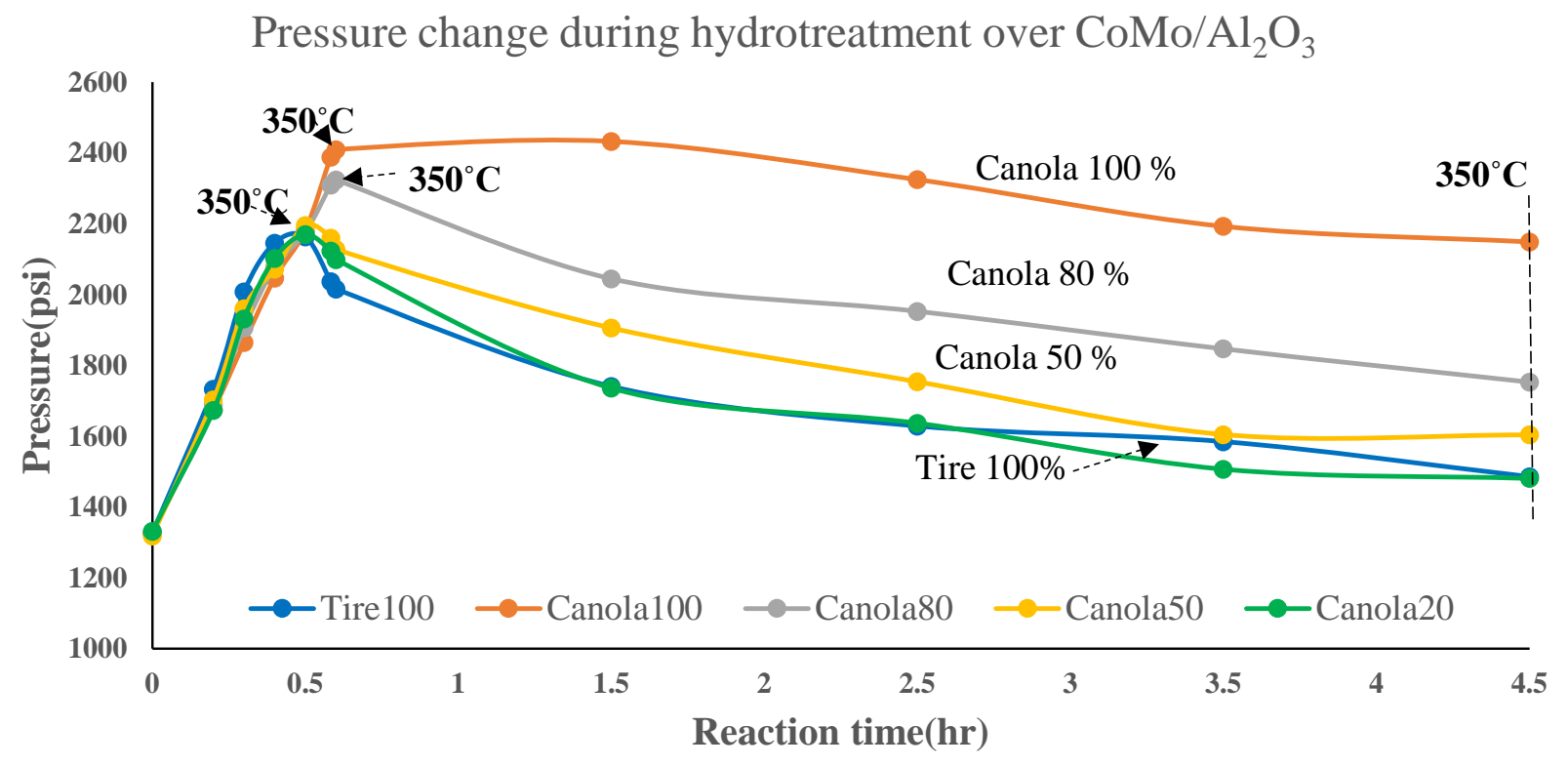

Figure 7. Pressure profiles during cohydrotreatment 


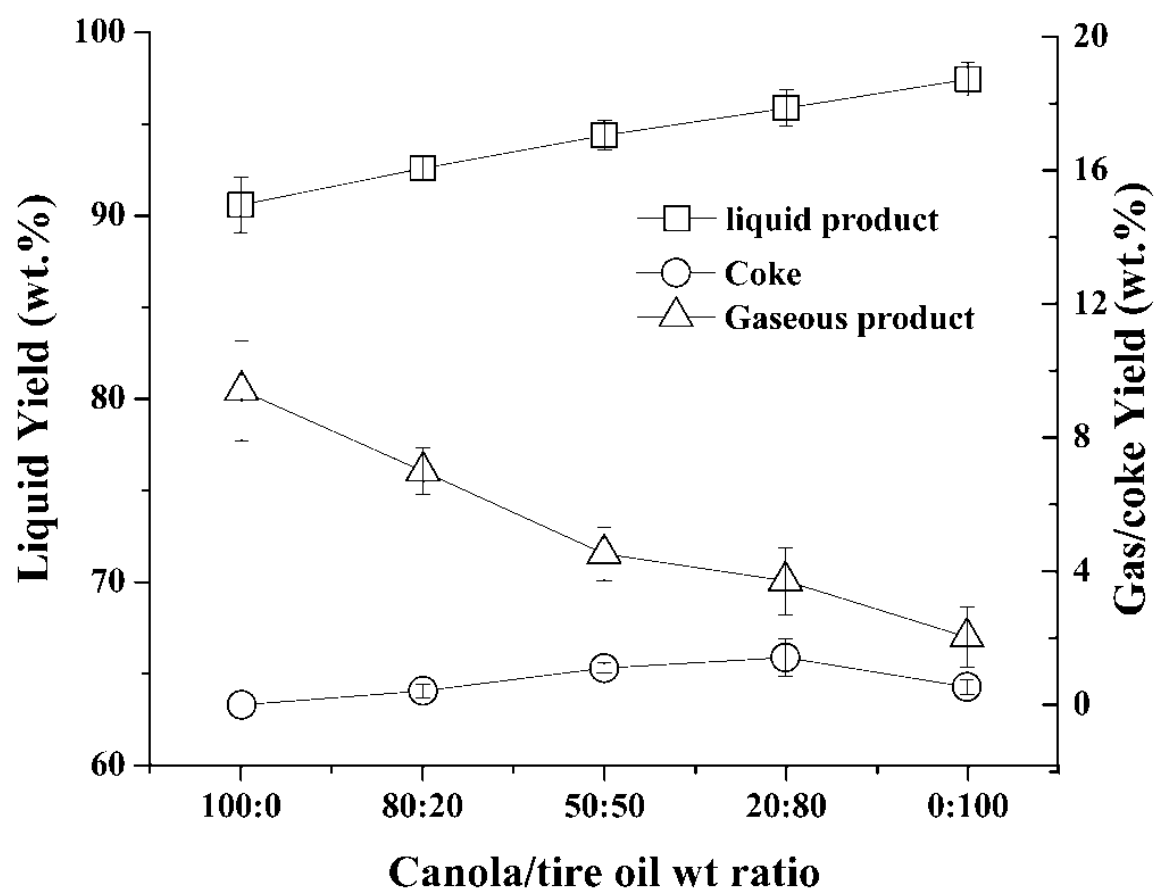

Figure 8 Product yields for the co-hydrotreatment of tire oil and canola oil 


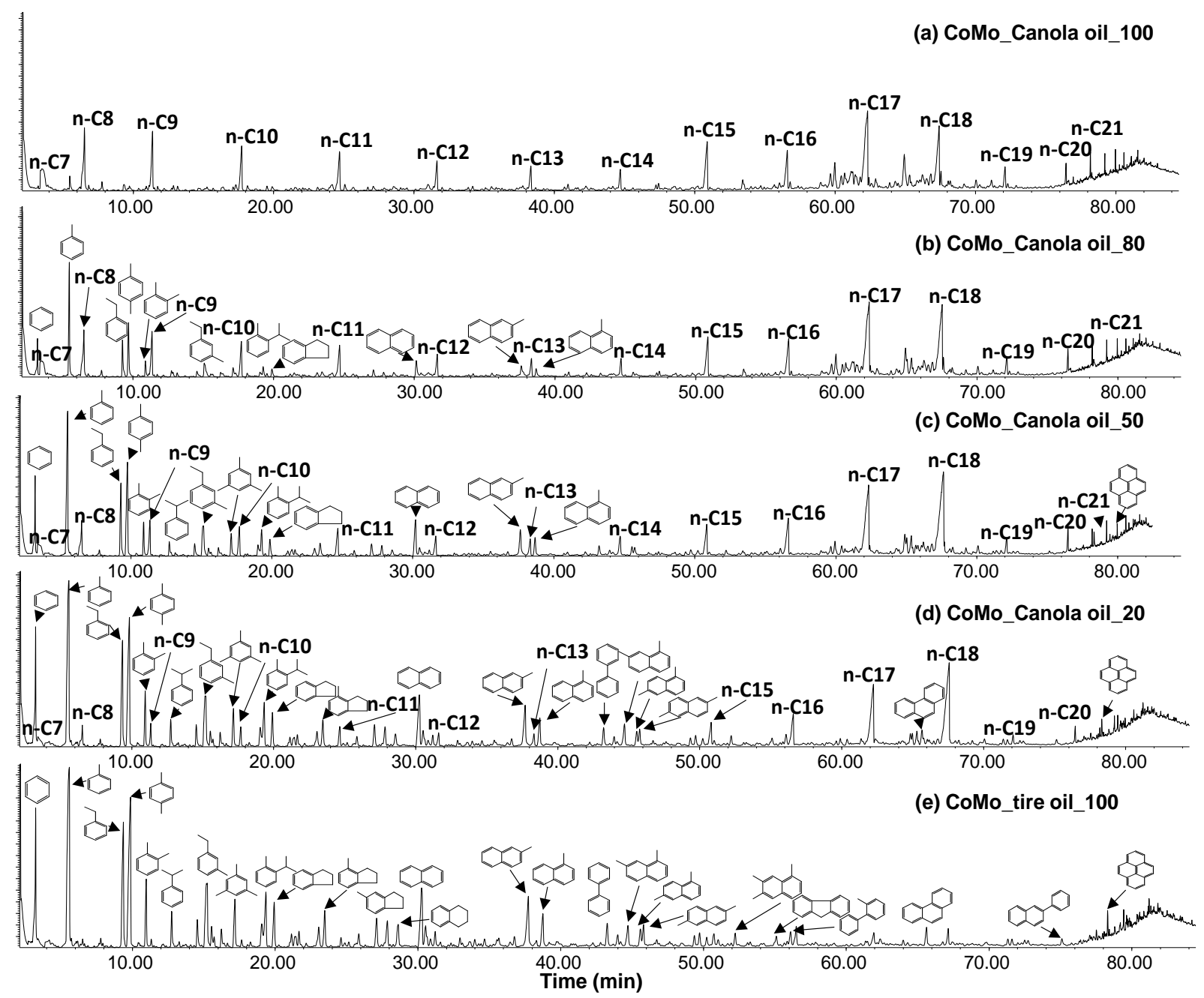

Figure 9. GC-MS characterization on liquid products from co-hydrotreatment 

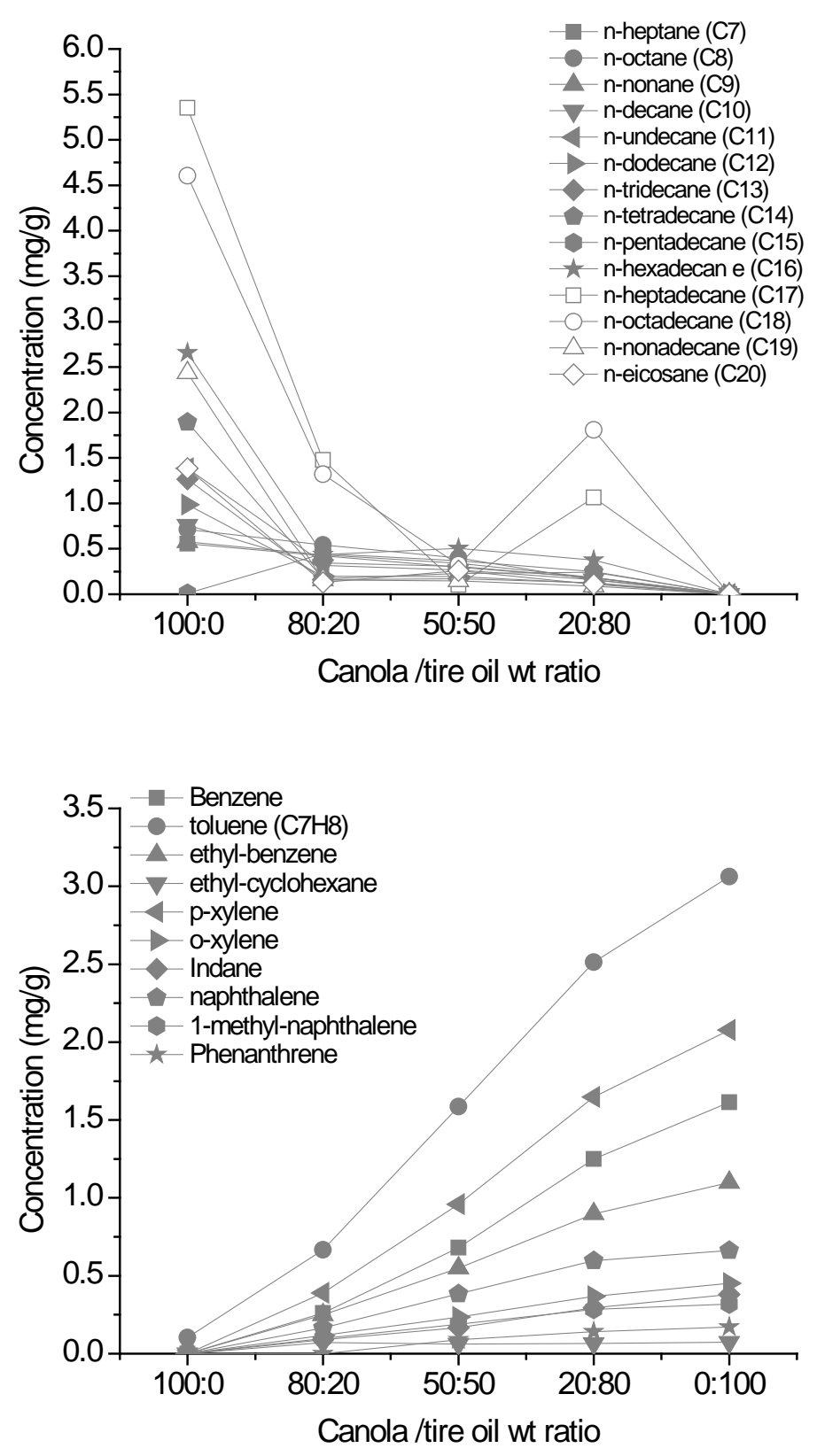

Figure 10. Yield of targeted compounds 


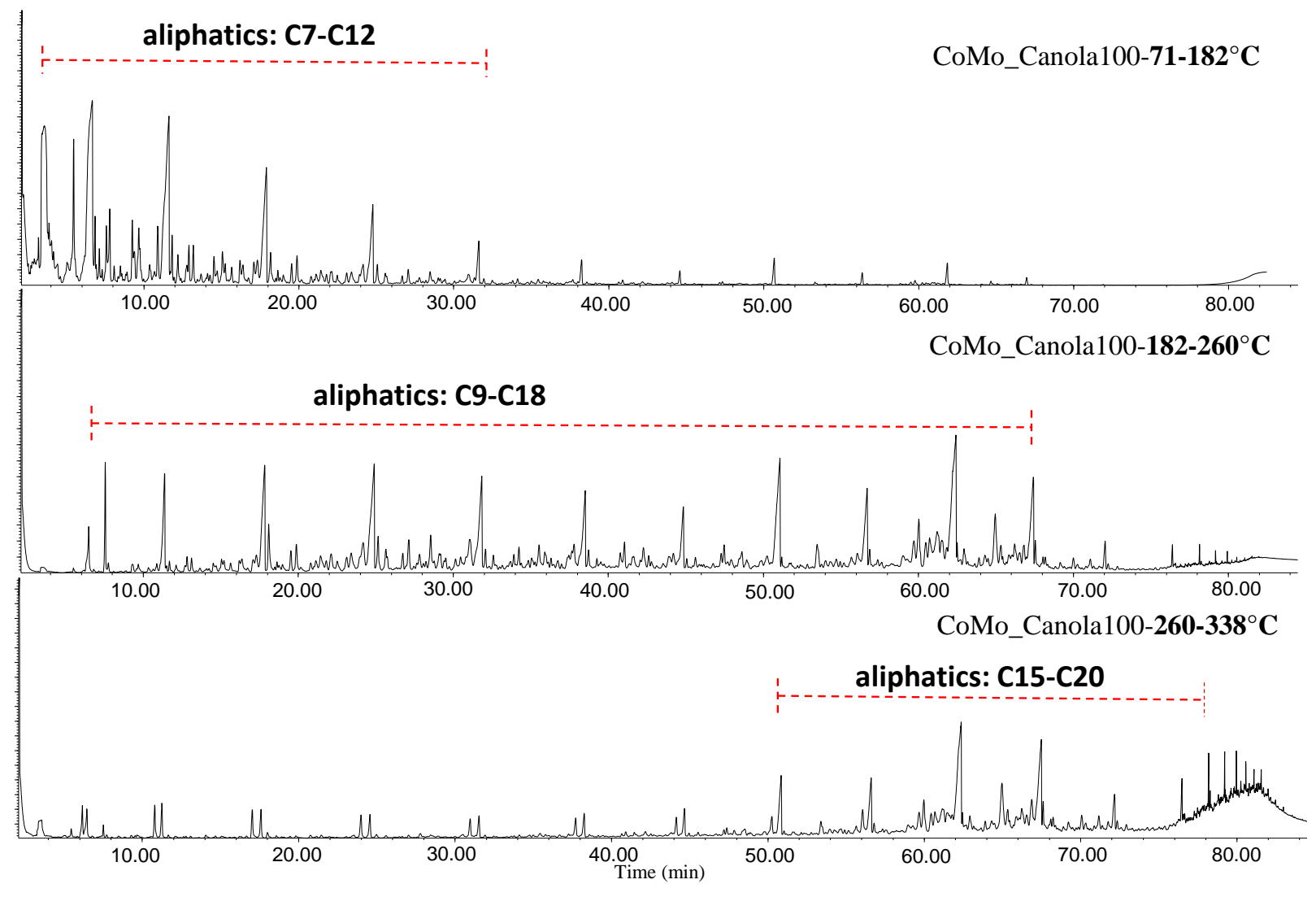

Figure 11. GC-MS of distillation cuts from hydrotreated canola 


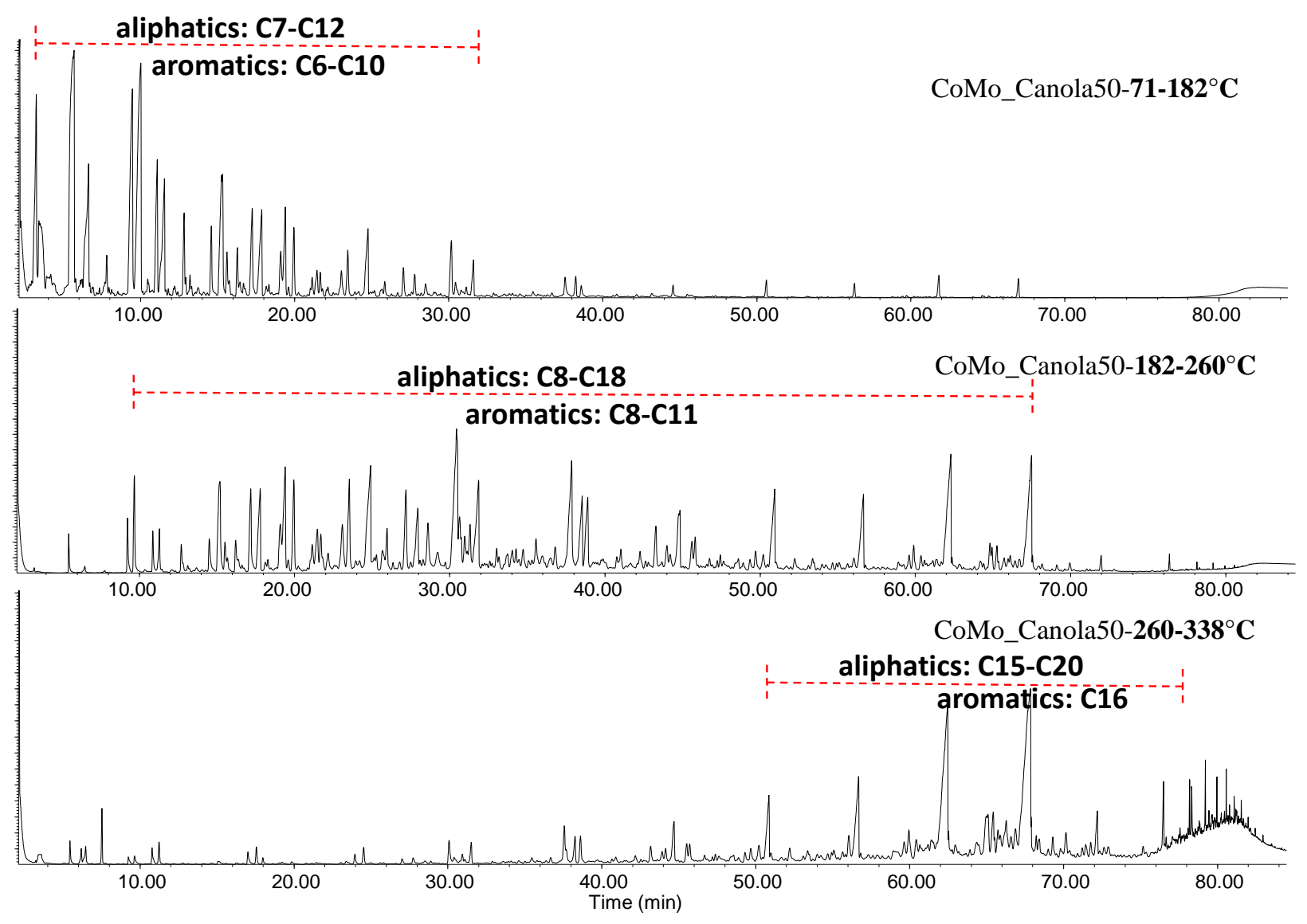

Figure 12. GC-MS of distillation cuts from hydrotreated canola-tires oil (50/50) 


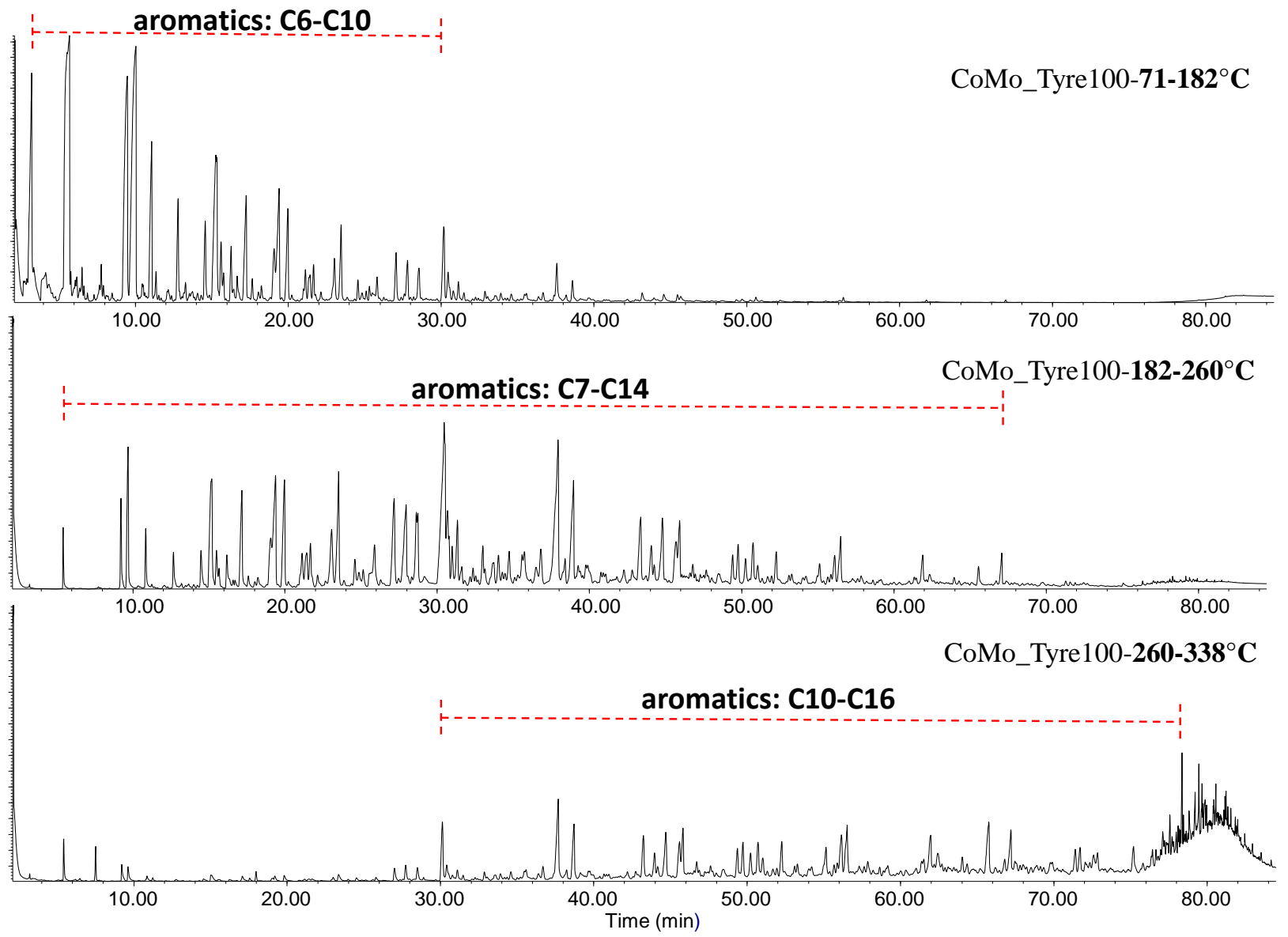

Figure 13. GC-MS on distillation cuts from hydrotreated tire oil 

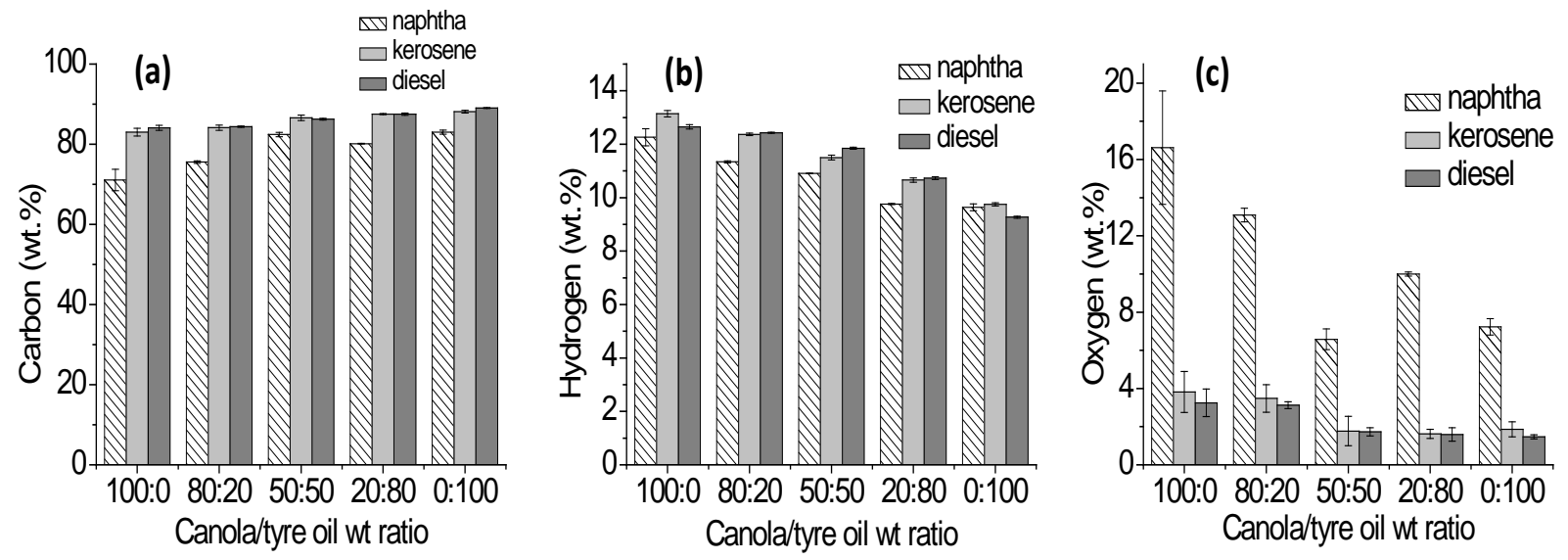

Figure 14. Elemental analysis for distillation cuts from hydrotreated oil 


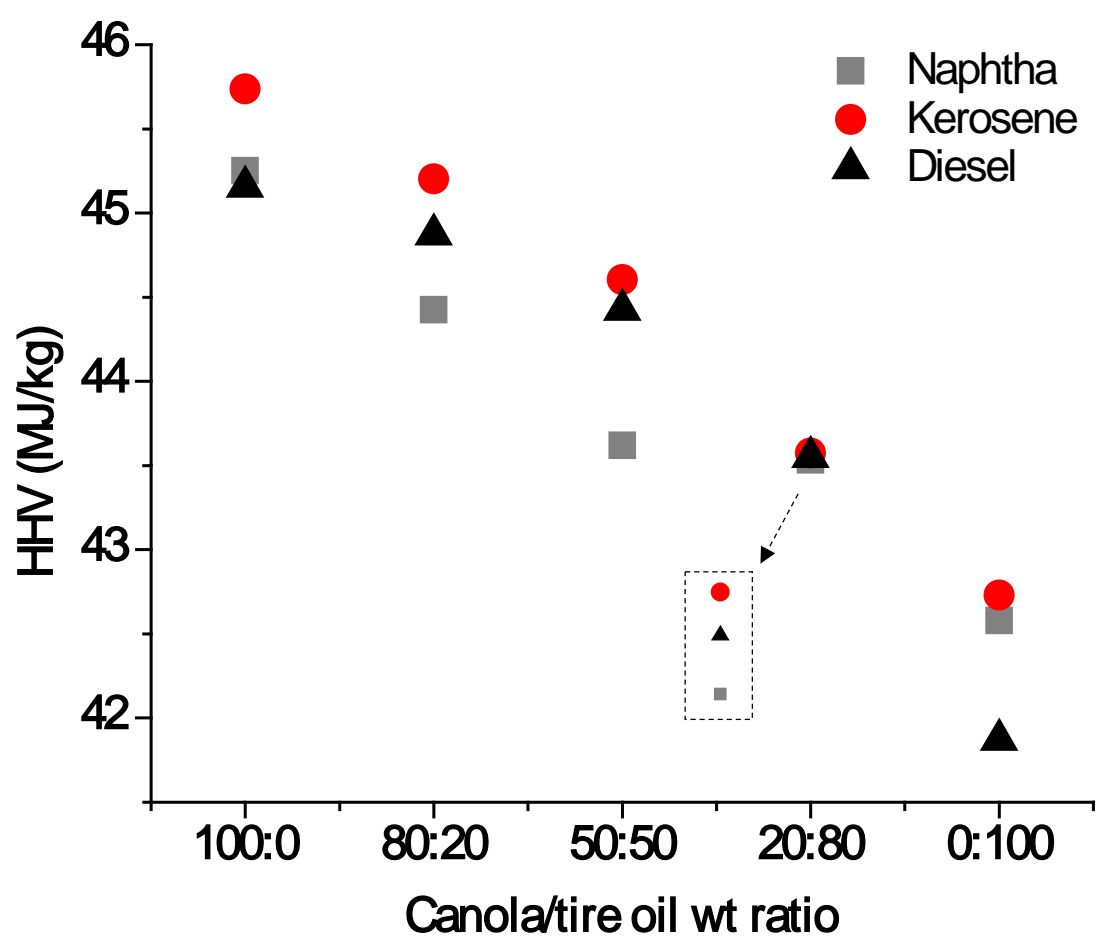

Figure 15. Calorific heating value of produced distillation cuts 


\section{List of Tables}

Table 1. BET surface area analysis on fresh and used $\mathrm{CoMo} / \mathrm{Al}_{2} \mathrm{O}_{3}$ catalysts

Table 2 Gas product distribution for the co-hydrotreatment of tire oil and canola oil

Table 3 GC-MS characterization on co-hydrotreatment product

Table 4 Elemental analysis for co-hydrotreatment of tire oil and canola oil

Table 5 Total acid number (TAN) for hydrotreated oils

Table 6 Mass balance on distillation cuts for tire oil/canola oil co-processing (wt. \%)

Table 7 Flash point determination of produced distillation cuts

Table 8 Kinematic viscosity determination (at $40^{\circ} \mathrm{C}$ ) of produced distillation cuts

Table 9 Carbonyl content determination of produced distillation cuts

Table 1. BET surface area analysis on fresh and used $\mathrm{CoMo} / \mathrm{Al}_{2} \mathrm{O}_{3}$ catalysts

\begin{tabular}{|c|c|c|c|c|}
\hline Catalyst & BET surface area & Micropore volume & Mesopore volume & Total pore volume \\
\hline
\end{tabular}




\begin{tabular}{lcccc}
\hline & $\left(\mathrm{m}^{2} / \mathrm{g}\right)^{\mathrm{a}}$ & $\left(\mathrm{cm}^{3} / \mathrm{g}\right)^{\mathrm{b}}$ & $\left(\mathrm{cm}^{3} / \mathrm{g}\right)$ & $\left(\mathrm{cm}^{3} / \mathrm{g}\right)^{\mathrm{c}}$ \\
\hline Fresh & 234 & 0.057 & 0.556 & 0.613 \\
Canola100 & 180 & 0.015 & 0.444 & 0.459 \\
Canola80 & 171 & 0.016 & 0.412 & 0.428 \\
Canola50 & 171 & 0.026 & 0.372 & 0.398 \\
Canola20 & 172 & 0.033 & 0.374 & 0.407 \\
Tire100 & 176 & 0.031 & 0.383 & 0.414 \\
\hline
\end{tabular}

${ }^{\mathrm{a}}$ BET surface area calculated from the adsorption of the $\mathrm{N}_{2}$ isotherm

${ }^{\mathrm{b}}$ Micropore volume calculated from $\mathrm{CO}_{2}$ adsorption using the Dubin-Radushkevich equation

${ }^{\mathrm{c}}$ Total pore volume calculated from $\mathrm{N}_{2}$ adsorption at $\mathrm{p} / \mathrm{p}_{0}=0.98$ and the mesopore volume calculated by the difference between total and micropore volume (no macropore as shown in the pore distribution curves)

Table 2. Gas product distribution for the co-hydrotreatment of tire oil and canola oil

\begin{tabular}{|c|c|c|c|c|c|c|c|}
\hline & \multicolumn{7}{|c|}{ Gas product distribution (mol. \%) } \\
\hline & $\mathbf{H}_{2}$ & $\mathrm{CO}$ & $\mathrm{CO}_{2}$ & $\mathrm{CH}_{4}$ & $\mathrm{C}_{2} \mathrm{H}_{6}$ & $\mathrm{C}_{3} \mathrm{H}_{8}$ & $\mathrm{n}-\mathrm{C}_{4} \mathrm{H}_{10}$ \\
\hline \multirow{2}{*}{ Hydrotreated-Canola oil_100 } & 71. & & & & & & \\
\hline & 6 & 2.7 & 20.7 & 2.7 & 2.0 & 0.3 & 0.0 \\
\hline \multirow{2}{*}{ Hydrotreated-Canola oil_80 } & 69. & & & & & & \\
\hline & 1 & 3.6 & 20.8 & 3.6 & 2.4 & 0.6 & 0.0 \\
\hline \multirow{2}{*}{ Hydrotreated-Canola oil_50 } & 69. & & & & & & \\
\hline & 8 & 6.0 & 15.2 & 5.9 & 2.5 & 0.7 & 0.0 \\
\hline Hydrotreated-Canola oil_20 & 75. & & & 0 & 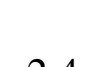 & & \\
\hline \multirow[b]{2}{*}{ Hydrotreated-Tyre oil_100 } & $\begin{array}{c}4 \\
77\end{array}$ & 8.3 & 4.7 & 8.3 & 2.4 & 0.6 & 0.2 \\
\hline & 0 & 10.0 & 0.1 & 10.1 & 2.3 & 0.5 & 0.1 \\
\hline
\end{tabular}

* Gas product distribution was quantified by GC-TCD/FID. 
Table 3. GC-MS characterization on tire oil and co-hydrotreatment products 


\begin{tabular}{|c|c|c|c|c|c|c|c|}
\hline \multirow[b]{2}{*}{$\begin{array}{l}\text { RT } \\
(\mathbf{m i n})\end{array}$} & \multirow[b]{2}{*}{ Identified compounds } & \multirow[b]{2}{*}{$\begin{array}{c}\text { Tire } \\
\text { oil }\end{array}$} & \multicolumn{5}{|c|}{ Peak area $\left(\times 10^{8}\right) / 0.05 \mathrm{~g} / \mathrm{L}$ sample } \\
\hline & & & $100: 0^{\mathrm{a}}$ & $80: 20$ & $50: 50$ & 20:80 & 0:100 \\
\hline 3.21 & benzene $\left(\mathrm{C}_{6} \mathrm{H}_{6}\right)$ & 1.12 & 0.00 & 2.50 & 6.16 & 10.09 & 12.24 \\
\hline 3.60 & n-heptane $\left(\mathrm{C}_{7} \mathrm{H}_{16}\right)$ & 0.00 & 7.48 & 5.50 & 3.92 & 2.40 & 0.00 \\
\hline 4.00 & methyl-cyclohexane $\left(\mathrm{C}_{7} \mathrm{H}_{14}\right)$ & 0.00 & 0.00 & 0.00 & 0.00 & 0.00 & 1.52 \\
\hline 5.50 & toluene $\left(\mathrm{C}_{7} \mathrm{H}_{8}\right)$ & 2.56 & 1.52 & 9.47 & 19.77 & 28.34 & 32.87 \\
\hline 6.50 & n-octane $\left(\mathrm{C}_{8} \mathrm{H}_{18}\right)$ & 0.00 & 8.94 & 6.96 & 5.21 & 2.05 & 0.00 \\
\hline 7.76 & ethyl-cyclohexane $\left(\mathrm{C}_{8} \mathrm{H}_{16}\right)$ & 0.00 & 0.00 & 0.87 & 0.70 & 0.78 & 0.88 \\
\hline 9.25 & ethyl-benzene $\left(\mathrm{C}_{8} \mathrm{H}_{10}\right)$ & 0.72 & 0.00 & 3.71 & 8.38 & 13.43 & 16.23 \\
\hline 9.68 & p-xylene $\left(\mathrm{C}_{8} \mathrm{H}_{10}\right)$ & 1.96 & 0.00 & 5.81 & 13.53 & 21.67 & 26.27 \\
\hline 10.90 & o-xylene $\left(\mathrm{C}_{8} \mathrm{H}_{10}\right)$ & 1.26 & 0.00 & 1.63 & 3.45 & 5.49 & 6.70 \\
\hline 11.37 & n-nonane $\left(\mathrm{C}_{9} \mathrm{H}_{20}\right)$ & 0.00 & 7.34 & 5.61 & 4.47 & 2.43 & 0.00 \\
\hline 12.74 & 1-methylethyl-benzene $\left(\mathrm{C}_{9} \mathrm{H}_{12}\right)$ & 0.08 & 0.00 & 0.00 & 1.55 & 2.97 & 3.62 \\
\hline 14.53 & propyl-benzene $\left(\mathrm{C}_{9} \mathrm{H}_{12}\right)$ & 0.16 & 0.00 & 0.00 & 0.00 & 0.00 & 3.19 \\
\hline 15.07 & 1-ethyl-4-methyl-benzene $\left(\mathrm{C}_{9} \mathrm{H}_{12}\right)$ & 0.65 & 0.00 & 2.85 & 6.44 & 6.10 & 8.33 \\
\hline 15.23 & 1-ethyl-2-methyl-benzene $\left(\mathrm{C}_{9} \mathrm{H}_{12}\right)$ & 0.15 & 0.00 & 0.00 & 0.00 & 0.00 & 4.78 \\
\hline 15.54 & 1,2,3-trimethyl-benzene $\left(\mathrm{C}_{9} \mathrm{H}_{12}\right)$ & 0.00 & 0.00 & 0.00 & 0.00 & 0.00 & 2.43 \\
\hline 15.73 & $\begin{array}{l}\text { 1-methyl-4-(1-methylethyl)-cyclohexane } \\
\left(\mathrm{C}_{10} \mathrm{H}_{20}\right)\end{array}$ & 0.00 & 0.00 & 0.00 & 0.00 & 0.00 & 1.06 \\
\hline 16.23 & 1-ethyl-3-methyl-benzene $\left(\mathrm{C}_{9} \mathrm{H}_{12}\right)$ & 0.18 & 0.00 & 0.00 & 0.00 & 0.00 & 1.99 \\
\hline 17.12 & 1,2,4-trimethyl-benzene $\left(\mathrm{C}_{9} \mathrm{H}_{12}\right)$ & 0.52 & 0.00 & 0.00 & 3.15 & 4.80 & 6.01 \\
\hline 17.73 & n-decane $\left(\mathrm{C}_{10} \mathrm{H}_{22}\right)$ & 0.00 & 11.05 & 4.81 & 4.05 & 2.41 & 0.00 \\
\hline 19.06 & 1,3,5-trimethyl-benzene $\left(\mathrm{C}_{9} \mathrm{H}_{12}\right)$ & 0.02 & 0.00 & 0.00 & 0.00 & 0.00 & 3.74 \\
\hline 19.25 & 1-methyl-2-(1-methylethyl)-benzene $\left(\mathrm{C}_{10} \mathrm{H}_{14}\right)$ & 0.03 & 0.00 & 1.33 & 3.50 & 6.17 & 7.79 \\
\hline 19.88 & Indene $\left(\mathrm{C}_{9} \mathrm{H}_{10}\right)$ & 0.05 & 0.00 & 1.17 & 2.41 & 4.39 & 5.65 \\
\hline 21.67 & 2-ethyl-1,4-dimethyl-benzene $\left(\mathrm{C}_{10} \mathrm{H}_{14}\right)$ & 0.01 & 0.00 & 0.00 & 0.00 & 0.00 & 1.85 \\
\hline 23.04 & 1-methyl-4-(1-methylethyl)-benzene $\left(\mathrm{C}_{10} \mathrm{H}_{14}\right)$ & 0.17 & 0.00 & 0.00 & 1.61 & 2.74 & 3.36 \\
\hline 23.44 & 1-methyl-indene $\left(\mathrm{C}_{10} \mathrm{H}_{12}\right)$ & 0.23 & 0.00 & 0.00 & 2.34 & 3.81 & 4.74 \\
\hline 24.70 & n-undecane $\left(\mathrm{C}_{11} \mathrm{H}_{24}\right)$ & 0.00 & 18.77 & 5.20 & 4.65 & 2.69 & 0.00 \\
\hline 25.86 & 1,2,4,5-tetramethyl-benzene $\left(\mathrm{C}_{10} \mathrm{H}_{14}\right)$ & 0.11 & 0.00 & 0.00 & 0.00 & 0.00 & 1.76 \\
\hline 27.07 & 2,3-dihydro-4-methyl-1H-indene $\left(\mathrm{C}_{10} \mathrm{H}_{12}\right)$ & 0.00 & 0.00 & 0.00 & 1.92 & 3.22 & 4.09 \\
\hline 27.82 & 2,3-dihydro-5-methyl-1H-indene $\left(\mathrm{C}_{10} \mathrm{H}_{12}\right)$ & 0.49 & 0.00 & 0.00 & 1.56 & 2.90 & 3.77 \\
\hline 30.14 & naphthalene $\left(\mathrm{C}_{10} \mathrm{H}_{8}\right)$ & 0.98 & 0.00 & 2.52 & 6.12 & 9.57 & 10.62 \\
\hline 30.54 & 2,3-dihydro-1,6-dimethyl-1H-indene $\left(\mathrm{C}_{11} \mathrm{H}_{14}\right)$ & 0.06 & 0.00 & 0.00 & 0.00 & 0.00 & 3.94 \\
\hline 31.20 & 2,3-dihydro-4,7-dimethyl-1H-indene $\left(\mathrm{C}_{11} \mathrm{H}_{14}\right)$ & 0.03 & 0.00 & 0.00 & 0.00 & 0.00 & 2.13 \\
\hline 31.64 & n-dodecane $\left(\mathrm{C}_{12} \mathrm{H}_{26}\right)$ & 0.00 & 15.17 & 3.12 & 3.06 & 1.87 & 0.00 \\
\hline 37.60 & 2-methyl-naphthalene $\left(\mathrm{C}_{11} \mathrm{H}_{10}\right)$ & 0.66 & 0.00 & 2.45 & 5.25 & 7.97 & 9.53 \\
\hline 38.33 & n-tridecane $\left(\mathrm{C}_{13} \mathrm{H}_{28}\right)$ & 0.00 & 19.15 & 2.51 & 2.71 & 1.97 & 0.00 \\
\hline 38.66 & 1-methyl-naphthalene $\left(\mathrm{C}_{11} \mathrm{H}_{10}\right)$ & 0.44 & 0.00 & 1.39 & 2.91 & 4.48 & 5.04 \\
\hline 43.21 & biphenyl $\left(\mathrm{C}_{12} \mathrm{H}_{10}\right)$ & 0.27 & 0.00 & 0.00 & 1.71 & 2.81 & 3.42 \\
\hline 44.69 & 1,7-dimethyl-naphthalene $\left(\mathrm{C}_{12} \mathrm{H}_{12}\right)$ & 0.22 & 0.00 & 0.00 & 0.00 & 0.00 & 3.62 \\
\hline 44.71 & n-tetradecane $\left(\mathrm{C}_{14} \mathrm{H}_{30}\right)$ & 0.00 & 27.57 & 2.65 & 3.61 & 3.80 & 0.00 \\
\hline 45.54 & 2,7-dimethyl-naphthalene $\left(\mathrm{C}_{12} \mathrm{H}_{12}\right)$ & 0.19 & 0.00 & 0.73 & 1.36 & 2.22 & 2.71 \\
\hline 45.74 & 2,6-dimethyl-naphthalene $\left(\mathrm{C}_{12} \mathrm{H}_{12}\right)$ & 0.19 & 0.00 & 0.56 & 1.47 & 2.43 & 2.93 \\
\hline 49.71 & 2-methyl-1,1-biphenyl $\left(\mathrm{C}_{13} \mathrm{H}_{12}\right)$ & 0.11 & 0.00 & 0.76 & 1.18 & 1.59 & 1.97 \\
\hline 50.23 & 3-methyl-1,1-biphenyl $\left(\mathrm{C}_{13} \mathrm{H}_{12}\right)$ & 0.12 & 0.00 & 0.94 & 1.09 & 1.27 & 1.46 \\
\hline 50.89 & n-pentadecane $\left(\mathrm{C}_{15} \mathrm{H}_{32}\right)$ & 0.00 & 41.82 & 7.07 & 5.84 & 3.93 & 0.00 \\
\hline 52.23 & 1,6,7-trimethyl-naphthalene $\left(\mathrm{C}_{13} \mathrm{H}_{14}\right)$ & 0.09 & 0.00 & 0.40 & 1.15 & 1.48 & 1.81 \\
\hline 55.11 & fluorene $\left(\mathrm{C}_{13} \mathrm{H}_{10}\right)$ & 0.00 & 0.00 & 0.49 & 0.75 & 1.63 & 2.01 \\
\hline 56.10 & 4-methyl-1,1-biphenyl $\left(\mathrm{C}_{13} \mathrm{H}_{12}\right)$ & 0.00 & 0.00 & 1.38 & 1.30 & 1.85 & 2.28 \\
\hline 56.59 & n-hexadecane $\left(\mathrm{C}_{16} \mathrm{H}_{34}\right)$ & 0.00 & 39.07 & 6.97 & 8.06 & 6.02 & 0.00 \\
\hline 59.66 & 1-heptadecene $\left(\mathrm{C}_{17} \mathrm{H}_{34}\right)$ & 0.00 & 38.94 & 2.23 & 1.40 & 0.72 & 0.00 \\
\hline 59.97 & 3-heptadecene $-\mathrm{E}\left(\mathrm{C}_{17} \mathrm{H}_{34}\right)$ & 0.00 & 42.83 & 3.54 & 2.11 & 1.24 & 0.00 \\
\hline 60.68 & 8-heptadecene - $\mathrm{Z}\left(\mathrm{C}_{17} \mathrm{H}_{34}\right)$ & 0.00 & 35.61 & 2.84 & 1.37 & 0.32 & 0.00 \\
\hline 61.14 & 2-methyl-hexadecene- $\mathrm{Z}\left(\mathrm{C}_{17} \mathrm{H}_{34}\right)$ & 0.00 & 37.63 & 3.57 & 1.07 & 0.30 & 0.00 \\
\hline 61.43 & 8-heptadecene - $\mathrm{E}\left(\mathrm{C}_{17} \mathrm{H}_{34}\right)$ & 0.00 & 37.66 & 2.86 & 1.27 & 1.01 & 0.00 \\
\hline
\end{tabular}

${ }^{\mathrm{a}}$ Canola and tire oil weight ratio 
Table 3. (Continuation).......

\begin{tabular}{|c|c|c|c|c|c|c|c|}
\hline \multirow{2}{*}{$\begin{array}{l}\text { RT } \\
\text { (min) }\end{array}$} & \multirow{2}{*}{ Identified compounds } & \multicolumn{6}{|c|}{ Peak area $\left(\times 10^{8}\right)$} \\
\hline & & Tire oil & 100:0 ${ }^{\mathrm{a}}$ & 80:20 & $50: 50$ & 20:80 & $0: 100$ \\
\hline 61.73 & 2-methyl-hexadecene- $\mathrm{E}\left(\mathrm{C}_{17} \mathrm{H}_{34}\right)$ & 0.00 & 21.52 & 1.50 & 0.16 & 0.50 & 0.00 \\
\hline 62.17 & n-heptadecane $\left(\mathrm{C}_{17} \mathrm{H}_{36}\right)$ & 0.00 & 71.85 & 22.75 & 1.55 & 16.69 & 0.00 \\
\hline 64.90 & 3-heptadecene $-\mathrm{Z}\left(\mathrm{C}_{17} \mathrm{H}_{34}\right)$ & 0.00 & 66.81 & 22.75 & 0.00 & 0.00 & 0.00 \\
\hline 65.63 & phenanthrene $\left(\mathrm{C}_{14} \mathrm{H}_{10}\right)$ & 0.00 & 0.00 & 0.00 & 1.14 & 2.20 & 2.79 \\
\hline 67.41 & n-octadecane $\left(\mathrm{C}_{18} \mathrm{H}_{38}\right)$ & 0.00 & 63.26 & 20.49 & 5.16 & 27.47 & 0.00 \\
\hline 67.53 & E-7-octadecene $\left(\mathrm{C}_{18} \mathrm{H}_{36}\right)$ & 0.00 & 43.33 & 1.99 & 0.00 & 0.00 & 0.00 \\
\hline 72.10 & n-nonadecane $\left(\mathrm{C}_{19} \mathrm{H}_{40}\right)$ & 0.00 & 36.12 & 2.44 & 2.29 & 1.32 & 0.00 \\
\hline 75.11 & 2-phenylnaphthalene $\left(\mathrm{C}_{16} \mathrm{H}_{12}\right)$ & 0.00 & 0.00 & 0.00 & 0.92 & 1.01 & 1.14 \\
\hline 76.44 & eicosane $\left(\mathrm{C}_{20} \mathrm{H}_{42}\right)$ & 0.00 & 21.43 & 2.04 & 4.13 & 1.70 & 0.00 \\
\hline
\end{tabular}

Table 4. Elemental analysis for co-hydrotreatment of tire oil and canola oil (on as received or produced basis)

\begin{tabular}{lccccc}
\hline & $\mathbf{C}$ & $\mathbf{H}$ & $\mathbf{N}$ & $\mathbf{S}$ & $\mathbf{O}^{*}$ \\
\hline Canola oil & $77.1 \pm 0.2$ & $11.4 \pm 0.1$ & - & - & $11.5 \pm 0.2$ \\
Hydrotreated Canola oil-100 & $83.9 \pm 0.1$ & $12.9 \pm 0.1$ & - & - & $3.2 \pm 0.1$ \\
Hydrotreated Canola oil-80 & $84.6 \pm 1.0$ & $12.2 \pm 0.2$ & $0.1 \pm 0.01$ & $0.18 \pm 0.00$ & $2.92 \pm 1.1$ \\
Hydrotreated Canola oil-50 & $79.9 \pm 0.9$ & $11.0 \pm 0.2$ & $0.2 \pm 0.01$ & $0.26 \pm 0.01$ & $8.54 \pm 1.1$ \\
Hydrotreated Canola oil-20 & $86.0 \pm 0.4$ & $10.1 \pm 0.1$ & $0.2 \pm 0.00$ & $0.28 \pm 0.01$ & $3.42 \pm 0.5$ \\
Hydrotreated Tire oil-100 & $86.4 \pm 0.6$ & $9.3 \pm 0.1$ & $0.2 \pm 0.01$ & $0.22 \pm 0.03$ & $3.88 \pm 0.7$ \\
Tire oil & $85.8 \pm 0.7$ & $8.7 \pm 0.1$ & $0.6 \pm 0.01$ & $1.12 \pm 0.03$ & $3.88 \pm 0.8$ \\
\hline
\end{tabular}

*by difference

Table 5. Total acid number (TAN) for hydrotreated oils

\begin{tabular}{lcc}
\hline & \multicolumn{3}{c}{ Total acid number (TAN) } \\
& & [mgKOH/g oil $]$ \\
\cline { 2 - 3 } & Feedstock & Hydrotreated oils \\
\hline Hydrotreated Canola oil-100 & 0.0 & 10.5 \\
Hydrotreated -Canola oil-80 & 1.7 & 9.9 \\
Hydrotreated -Canola oil-50 & 4.2 & 4.1 \\
Hydrotreated -Canola oil-20 & 6.8 & 2.4 \\
Hydrotreated -Tire oil-100 & 8.5 & 0.1 \\
\hline
\end{tabular}


Table 6. Mass balance on distillation cuts for tire oil/canola oil co-processing (wt. \%)

\begin{tabular}{lcccccc}
\hline & $\begin{array}{r}\text { naphtha } \\
71-182^{\circ} \mathrm{C}\end{array}$ & $\begin{array}{r}\text { kerosene } \\
182-260^{\circ} \mathrm{C}\end{array}$ & $\begin{array}{c}\text { diesel } \\
260- \\
338^{\circ} \mathrm{C}\end{array}$ & $\begin{array}{c}\text { gas oil } \\
338- \\
566^{\circ} \mathrm{C}\end{array}$ & residue & Total \\
\hline Tire oil & 29.9 & 18.0 & 20.1 & 9.8 & 16.3 & 94.1 \\
\hline Hydrotreated-Canola_100 & 13.4 & 17.6 & 60.2 & N/A & 2.7 & 93.9 \\
Hydrotreated-Canola_80 & 17.7 & 11.8 & 58.5 & N/A & 6.4 & 94.3 \\
Hydrotreated-Canola_50 & 22.1 & 13.4 & 48.8 & N/A & 8.9 & 93.2 \\
Hydrotreated-Canola_20 & 30.0 & 18.6 & 35.4 & N/A & 11.6 & 95.7 \\
Hydrotreated-Tire_100 & 36.8 & 20.2 & 27.3 & N/A & 11.7 & 96.0 \\
\hline
\end{tabular}

Table 7. Flash point determination of produced distillation cuts

\begin{tabular}{lccc}
\hline & \multicolumn{3}{c}{ Flash point $\left({ }^{\circ} \mathrm{C}\right)$} \\
\cline { 2 - 4 } & Feed & kerosene $\left(182-260^{\circ} \mathrm{C}\right)$ & $\operatorname{diesel}\left(260-338^{\circ} \mathrm{C}\right)$ \\
\hline Hydrotreated-Canola oil-100 & 275 & 40 & 49 \\
Hydrotreated-Canola oil-80 & 36 & 50 & 55 \\
Hydrotreated-Canola oil-50 & $<20$ & 50 & 55 \\
Hydrotreated-Canola oil-20 & $<20$ & 51 & 56 \\
Hydrotreated-Tire oil-100 & $<20$ & 49 & 54 \\
\hline
\end{tabular}

Table 8. Kinematic viscosity determination $\left(\right.$ at $40^{\circ} \mathrm{C}$ ) of produced distillation cuts

\begin{tabular}{lcccc}
\hline & Feed $\left(\mathrm{mm}^{2} / \mathrm{s}\right)$ & Naphtha $\left(\mathrm{mm}^{2} / \mathrm{s}\right)$ & Kerosene $\left(\mathrm{mm}^{2} / \mathrm{s}\right)$ & Diesel $\left(\mathrm{mm}^{2} / \mathrm{s}\right)$ \\
\hline Hydrotreated-Canola-100 & 36.351 & 0.849 & 1.995 & 3.551 \\
Hydrotreated-Canola-80 & 23.952 & 0.717 & 2.150 & 4.217 \\
Hydrotreated-Canola-50 & 15.405 & 0.705 & 2.005 & 4.095 \\
Hydrotreated-Canola-20 & 5.707 & 0.679 & 1.646 & 4.601 \\
Hydrotreated-Tire-100 & 3.743 & 0.685 & 1.937 & 6.820 \\
\hline
\end{tabular}

Table 9. Carbonyl content determination of produced distillation cuts

\begin{tabular}{lcccc}
\hline & \multicolumn{4}{c}{ Concentration of carbonyl $(\mu \mathrm{g} / \mathrm{g})$} \\
\cline { 2 - 5 } Sample & Feed & Naphtha & Kerosene & Diesel \\
\hline Hydrotreated-Canola_100 & 22.9 & 967.0 & 442.5 & 583.4 \\
Hydrotreated-Canola_80 & 62.5 & 912.6 & 252.1 & 564.6 \\
Hydrotreated-Canola_50 & 122.0 & 235.4 & 63.9 & 333.1 \\
Hydrotreated-Canola_20 & 181.5 & 15.4 & 26.8 & 207.4
\end{tabular}




\section{Graphical Abstract}

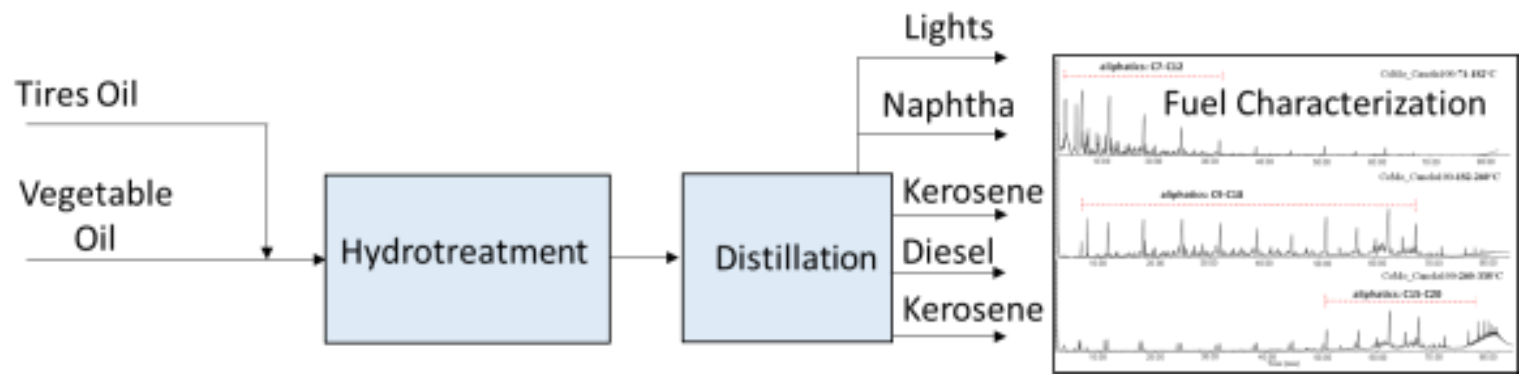

